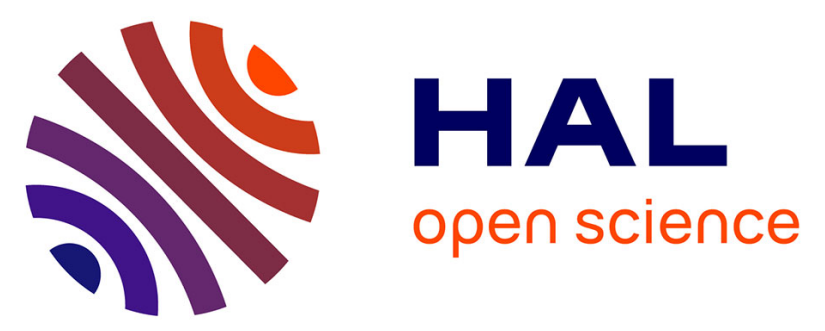

\title{
Laser impulse coupling measurements at 400 fs and 80 ps using the LULI facility at $1057 \mathrm{~nm}$ wavelength
}

Claude R. Phipps, Michel Boustié, Jean Marc Chevalier, Sophie D. Baton, Erik Brambrink, Laurent Berthe, Mathieu Schneider, Laurent Videau, Séverine A.E. Boyer, Stefan Scharring

\section{To cite this version:}

Claude R. Phipps, Michel Boustié, Jean Marc Chevalier, Sophie D. Baton, Erik Brambrink, et al.. Laser impulse coupling measurements at $400 \mathrm{fs}$ and $80 \mathrm{ps}$ using the LULI facility at $1057 \mathrm{~nm}$ wavelength. Journal of Applied Physics, 2017, 122, pp.Article number 193103. 10.1063/1.4997196 . hal02180913

\section{HAL Id: hal-02180913 https://hal.science/hal-02180913}

Submitted on 11 Jul 2019

HAL is a multi-disciplinary open access archive for the deposit and dissemination of scientific research documents, whether they are published or not. The documents may come from teaching and research institutions in France or abroad, or from public or private research centers.
L'archive ouverte pluridisciplinaire $\mathbf{H A L}$, est destinée au dépôt et à la diffusion de documents scientifiques de niveau recherche, publiés ou non, émanant des établissements d'enseignement et de recherche français ou étrangers, des laboratoires publics ou privés. 


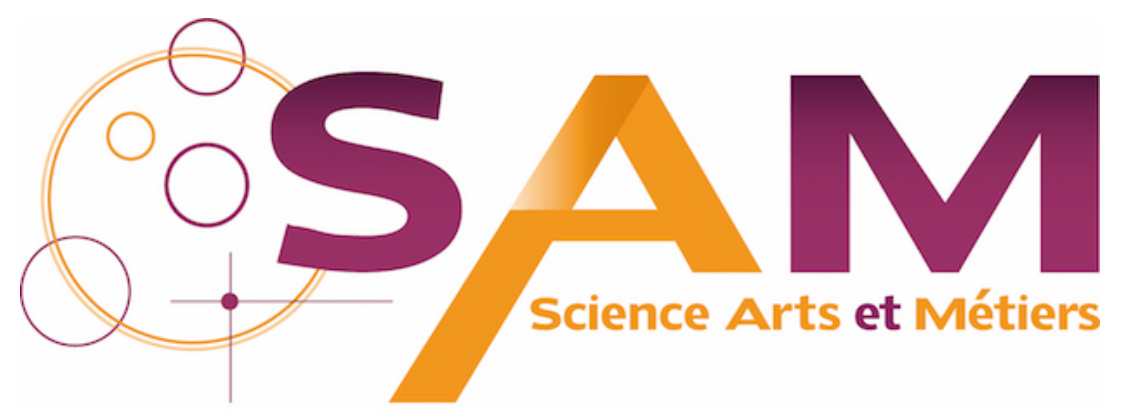

Archive Ouverte - Open Repository

\section{Science Arts \& Métiers (SAM)}

is an open access repository that collects the work of Arts et Métiers ParisTech researchers and makes it freely available over the web where possible.

This is an author-deposited version published in: https://sam.ensam.eu Handle ID: .http://hdl.handle.net/null

\section{To cite this version :}

Claude R. PHIPPS, Michel BOUSTIE, Jean Marc CHEVALIER, Sophie D. BATON, Erik BRAMBRINK, Laurent BERTHE, Mathieu SCHNEIDER, Laurent VIDEAU, Séverine A.E. BOYER, Stefan SCHARRING - Laser impulse coupling measurements at $400 \mathrm{fs}$ and $80 \mathrm{ps}$ using the LULI facility at $1057 \mathrm{~nm}$ wavelength - Journal of Applied Physics - Vol. Volume 122, Issue 19, n²1 November 2017, p. Article number $193103-2017$ 


\title{
Laser impulse coupling measurements at 400 fs and 80 ps using the LULI facility at $1057 \mathrm{~nm}$ wavelength
}

\author{
C. R. Phipps, ${ }^{1}$ M. Boustie, ${ }^{2}$ J.-M. Chevalier, ${ }^{3}$ S. Baton, ${ }^{4}$ E. Brambrink, ${ }^{4}$ L. Berthe,${ }^{5}$ \\ M. Schneider, ${ }^{5}$ L. Videau, ${ }^{6}$ S. A. E. Boyer, ${ }^{7}$ and S. Scharring ${ }^{8}$ \\ ${ }^{1}$ Photonic Associates, LLC, Santa Fe, New Mexico 87508, USA \\ ${ }^{2}$ CNRS-ENSMA, U. Poitiers, Futuroscope, France \\ ${ }^{3}$ CEA, DAM CESTA, Le Barp, France \\ ${ }^{4}$ LULI, CNRS-École Polytechnique-CEA-UPMC, 50 Palaiseau, France \\ ${ }^{5}$ CNRS-Arts et Metiers ParisTech, Paris, France \\ ${ }^{6}$ CEA, DAM, DIF, Arpajon, France \\ ${ }^{7}$ Mines ParisTech, CEMEF, Sophia Antipolis, France \\ ${ }^{8}$ DLR, Stuttgart, Germany
}

\begin{abstract}
At the École Polytechnique «LULI » facility, we have measured the impulse coupling coefficient $C_{\mathrm{m}}$ (target momentum per joule of incident laser light) with several target materials in vacuum, at $1057 \mathrm{~nm}$ and $400 \mathrm{fs}$ and $80 \mathrm{ps}$ pulse duration. A total of 64 laser shots were completed in a two-week experimental campaign, divided between the two pulse durations and among the materials. Our main purpose was to resolve wide discrepancies among reported values for $C_{\mathrm{m}}$ in the $100 \mathrm{ps}$ region, where many applications exist. A secondary purpose was to compare $C_{\mathrm{m}}$ at $400 \mathrm{fs}$ and $80 \mathrm{ps}$ pulse duration. The $80 \mathrm{ps}$ pulse was obtained by partial compression. Materials were Al, Ta, W, Au, and POM (polyoxymethylene, trade name Delrin). One application of these results is to pulsed laser ablation propulsion in space, including space debris re-entry, where narrow ranges in $C_{\mathrm{m}}$ and specific impulse $I_{\mathrm{sp}}$ spell the difference between dramatic and uneconomical performance. We had difficulty measuring mass loss from single shots. Imparted momentum in single laser shots was determined using pendulum deflection and photonic Doppler velocimetry. $C_{\mathrm{m}}$ was smaller at the $400 \mathrm{fs}$ pulse duration than at $80 \mathrm{ps}$. To our surprise, $C_{\mathrm{m}}$ for $\mathrm{Al}$ at $80 \mathrm{ps}$ was at most $30 \mathrm{~N} / \mathrm{MW}$ with $30 \mathrm{~kJ} / \mathrm{m}^{2}$ incident fluence. On the other extreme, polyoxymethylene (POM, trade name Delrin) demonstrated 770 N/MW under these conditions. Together, these results offer the possibility of designing a $C_{\mathrm{m}}$ value suited to an application, by mixing the materials appropriately. https://doi.org/10.1063/1.4997196
\end{abstract}

\section{INTRODUCTION: LASER ABLATION PROPULSION PARAMETERS FOR SHORT AND ULTRASHORT PULSES}

\section{A. Challenge}

The problem driving this work was the need for accurate impulse coupling parameters for practical short and ultrashort laser pulse durations, 80 ps and $400 \mathrm{fs}$, on common space materials. The most important of these are impulse coupling coefficient $C_{\mathrm{m}}$ and the laser-produced jet's specific impulse $I_{\text {sp }}$, a rocketry parameter related to average jet velocity $v_{\mathrm{E}}$ by the standard acceleration of gravity $\mathrm{g}_{\mathrm{o}}$

$$
I_{\mathrm{sp}}=v_{\mathrm{E}} / \mathrm{g}_{\mathrm{o}} .
$$

$I_{\mathrm{sp}}$ depends upon target mass loss $\delta m_{\mathrm{T}}$ during each pulse because the momentum given to the target by $W$ joules of incident laser light incident is

$$
C_{\mathrm{m}} W=\delta m_{\mathrm{T}} \mathrm{g}_{\mathrm{o}} I_{\mathrm{sp}} \quad \mathrm{N}-\mathrm{s}
$$

(see Fig. 1). Mass conservation requires $\delta m_{\mathrm{T}}=\delta m_{\mathrm{E}}$.

Their product gives the thrust efficiency of the ablation process. With $\psi=\left\langle v_{\mathrm{E}}{ }^{2}\right\rangle /\left\langle v_{\mathrm{E}}\right\rangle^{2}$,

$$
C_{\mathrm{m}} I_{\mathrm{sp}}=\left[2 /\left(\Psi \mathrm{g}_{\mathrm{o}}\right)\right] \eta_{\mathrm{AB}} .
$$

We take $\psi=1$ in this work, as explained below. This efficiency is just the ratio of the exhaust kinetic energy to incident laser energy.

Mass loss is very difficult to measure in a single pulse. To put this statement in perspective, using typical values for fluence $\Phi=30 \mathrm{~kJ} / \mathrm{m}^{2}$ on the target and $C_{\mathrm{m}}=35 \mathrm{~N} / \mathrm{MW}$ in an $A_{\mathrm{s}}=1 \mathrm{~cm}^{2}$ laser spot area

$$
\delta m_{\mathrm{T}}=A_{\mathrm{s}} C_{\mathrm{m}}^{2} \Phi /\left(2 \eta_{\mathrm{AB}}\right)
$$

which is less than two nanograms in typical single short pulse interactions.

It must be understood that Eqs. (1)-(4) parameters are convenient approximations to moments of real plasma velocity distributions, as we explain more fully in Sec. III, where we will also derive Eq. (4).

\section{B. Brief history of laser ablation}

The history of photon propulsion began ninety years ago with the studies by Tsander, ${ }^{1}$ Tsiolkovskii, ${ }^{2}$ and Oberth, ${ }^{3}$ leading to today's "solar sails." In 1953, Sänger published his concept for photon rockets ${ }^{4}$ even before the invention of lasers.

However, for usefully large forces-for example, enough to counteract gravity or accelerate a several-kg 


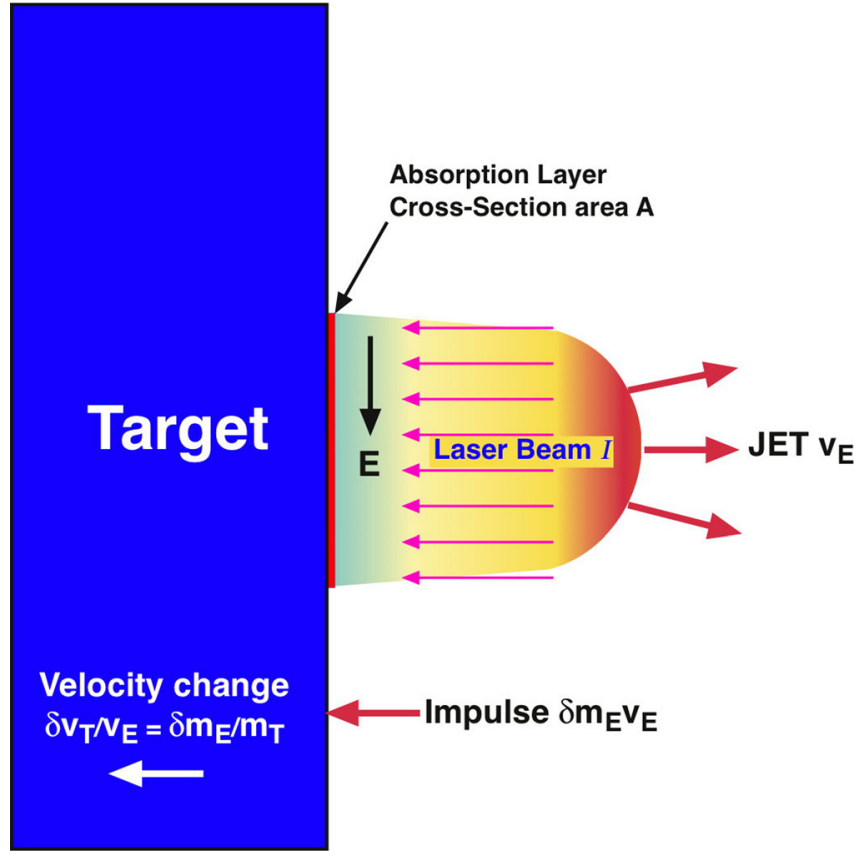

FIG. 1. Laser ablation impulse generation.

object to orbital speeds in a reasonable time, pure photon propulsion is too weak. Laser ablation propulsion (LAP), giving a $C_{\mathrm{m}}$ value four to five orders of magnitude larger, was first proposed by Kantrowitz ${ }^{5}$ in 1972.

Laser ablation propulsion operates, ideally in vacuum, by inducing a plasma jet from a target using a laser pulse, which transfers momentum to the target (Fig. 1). ${ }^{6}$
In Fig. 2, literature references for the data listed are as follows: a, b, c, d: aluminum, copper, graphite, and lead; ${ }^{7}$ e: aluminum; ${ }^{8} \mathrm{~g}, \mathrm{~h}, \mathrm{O}, \mathrm{P}$ : aluminum $;{ }^{9} \mathrm{i}, \mathrm{k}, \mathrm{l}, \mathrm{m}$ : tantalum, titanium, PMMA, and aluminum, w, x, A: aluminum, kevlar epoxy, and nylon, B, C: cellulose acetate ${ }^{10} \mathrm{n}$ : aluminum; ${ }^{11}$ $\mathrm{o}$ : aluminum, y: kevlar epoxy, and T, U: aluminum; ${ }^{12} \mathrm{p}, \mathrm{q}, \mathrm{r}$, $\mathrm{s}, \mathrm{t}, \mathrm{u}$ : beryllium, graphite, aluminum, zinc, silver, and tungsten; ${ }^{13} \mathrm{z}$ : copper; ${ }^{14} \mathrm{G}$ : titanium; ${ }^{15} \mathrm{H}$ : aluminum and $\mathrm{E}, \mathrm{F}$ : carbon phenolic and graphite; ${ }^{16} \mathrm{I}, \mathrm{J}, \mathrm{K}, \mathrm{L}, \mathrm{M}$ : titanium and grafoil; ${ }^{17} \mathrm{Q}$ : aluminum; ${ }^{18} \mathrm{R}$ : stainless steel; ${ }^{19} \mathrm{~S}$ : aluminum; ${ }^{20} \mathrm{Z}$, f: copper; ${ }^{21} \mathrm{~N}: \mathrm{Al} ;{ }^{22} 1: \mathrm{Ti}^{23} 2: \mathrm{Mo}{ }^{24}$ 3: W, 4: Au; 5: Li; 6: Fe and 7: glycidyl azide polymer; ${ }^{25} \mathrm{v}: \mathrm{Al}$ (simulation); ${ }^{26} \mathrm{~V}, \mathrm{~W}, \mathrm{X}, \mathrm{Y}: \mathrm{Al},{ }^{27}$ (all simulations, circular polarization, $\Theta_{\text {inc }}=0^{\circ}, 45^{\circ}, 60^{\circ}$, and $75^{\circ}$, respectively).

Even better efficiency than the continuous (CW) $\mathrm{CO}_{2}$ lasers envisioned as sources by Kantrowitz is obtained with pulsed laser sources. For high efficiency in laser ablation propulsion, the laser beam must use repetitive, high intensity pulses (e.g., $20 \mathrm{~kJ}, 10 \mathrm{ps}, 50 \mathrm{~Hz}$ ). There are several reasons for this recommendation. ${ }^{28}$ First, high $I_{\mathrm{sp}}$ has not been demonstrated by any reliable published data with $\mathrm{CW}$ lasers in vacuum. Second, our calculations ${ }^{29}$ show that the CW intensity on the target needed to achieve even low values of $I_{\mathrm{sp}}$ (about $1 \mathrm{GW} / \mathrm{m}^{2}$ ) requires a very high power laser (e.g., $1 \mathrm{GW}$ for a $1 \mathrm{~m}^{2}$ target at a distance of $200 \mathrm{~km}$ ). Second, CW laser interactions have a "welding torch" problem, generating lots of low-velocity splash which quickly destroys $I_{\mathrm{sp}}$ when compared to a 10 ps pulse stream. Third, CW laser thermal coupling to the target will be disastrous because of weak plasma shielding. Last, repetitive pulses can ensure plasma clearing between shots so that it does not interfere with propagation.

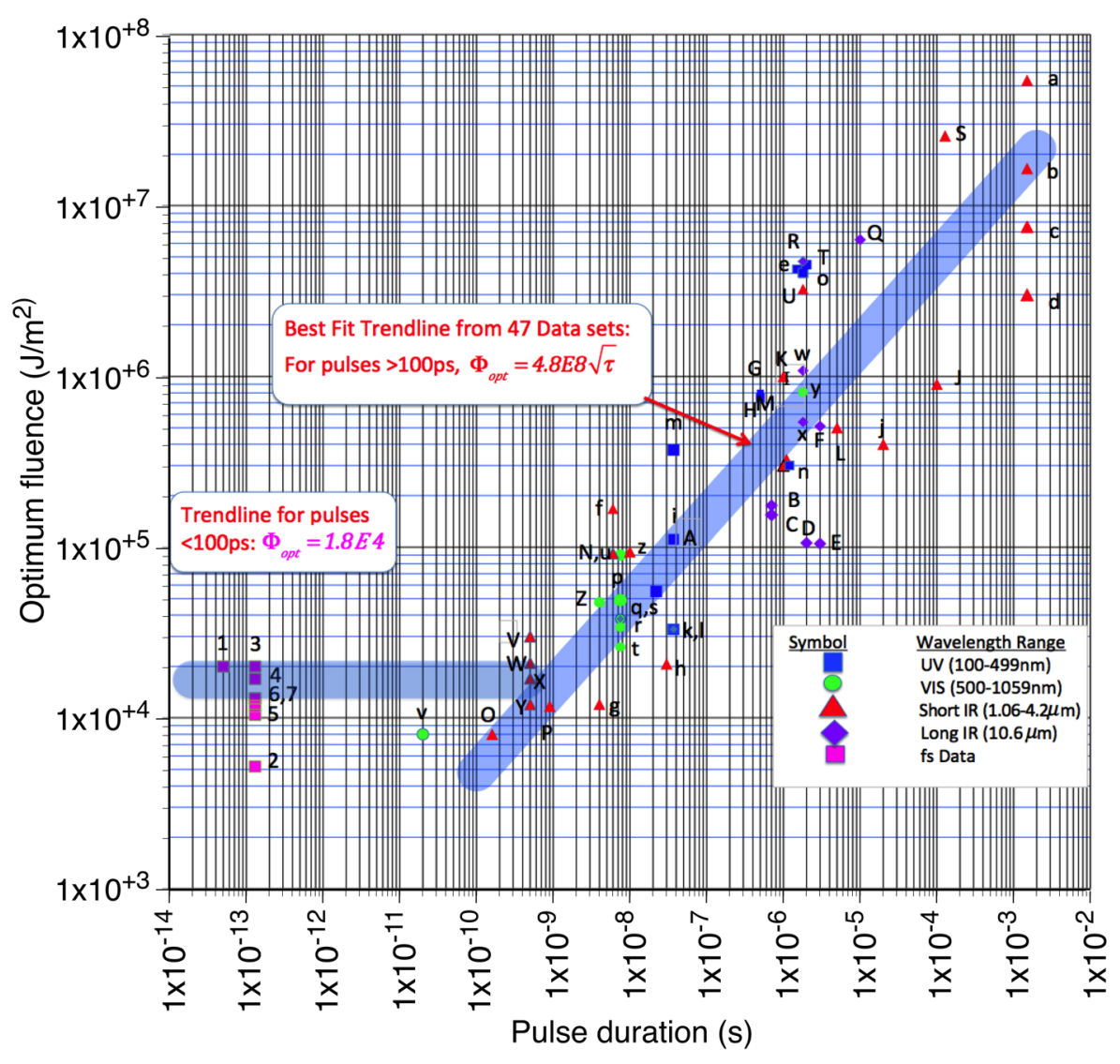

FIG. 2. Literature values for optimum fluence across a wide range of pulse durations. On the right (pulses longer than $100 \mathrm{ps}$ ), the trend is for $\Phi_{\mathrm{opt}}$ to increase with the square root of pulse duration. 
TABLE I. Existing Short Pulse $\mathrm{C}_{\mathrm{m}}$ Data (all $800 \mathrm{~nm}$ ).

\begin{tabular}{lcccc}
\hline \hline Fluence $\left(\mathrm{kJ} / \mathrm{m}^{2}\right)$ & $C_{\text {mopt }}(\mathrm{N} / \mathrm{MW})$ & Pulsewidth (fs) & Material & Reference \\
\hline 20 & 18 & 50 & $\mathrm{Ti}$ & 23 \\
5.2 & 42 & 130 & $\mathrm{Mo}$ & 24 \\
20 & 40 & 130 & $\mathrm{~W}$ & 25 \\
17 & 85 & 130 & $\mathrm{Au}$ & 25 \\
10 & 25 & 130 & $\mathrm{Li}$ & 25 \\
13 & 49 & 130 & $\mathrm{Fe}$ & 25 \\
13 & 25 & 130 & $\mathrm{GAP}$ & 25 \\
12 & 18 & 130 & $\mathrm{Al}$ & 25 \\
\hline \hline
\end{tabular}

Dozens of works have shown that ps and fs pulses give surgically clean material removal, suggesting ablation efficiency as well as low thermal coupling. ${ }^{30}$

\section{Short-pulse coupling data prior to our measurement program}

In Sec. III, we will see that $\mathrm{C}_{\mathrm{m}}$ should vary to first order with the square root of atomic mass, other factors being constant. Table I data are quite scattered with regard to this trend. The variation of the theoretically predicted ratio $C_{\mathrm{m}} /$ $A^{0.44}$ is too great to justify a trend in these data. In Table I, GAP refers to glycidyl azide polymer, an energetic material which gave giant results in ms-pulse propulsion work.

$C_{\mathrm{m}}$ is a relatively sensitive function of laser fluence delivered to the target. In the table, $C_{\mathrm{mopt}}$ refers to the maximum value of $C_{\mathrm{m}}$ which can be obtained as fluence varies (Fig. 3).

Why are there so few data? There are several reasons. First, measuring $C_{\mathrm{m}}$ is an unusual interest among ultrashort physics workers, most of whom are looking for an effect other than transferred momentum, which requires specialized equipment. Second, as we said in Sec. IA, it is difficult to measure mass loss with single pulses, and not so many lasers are capable of producing several $\mathrm{J}$ pulses in the fs region. We were fortunate to have the École Polytechnique "Elfie" laser available for our program.

\section{Required laser fluence on the target}

The main argument for short rather than long pulses is that longer pulses require progressively more pulse energy according to $\tau^{1 / 2}$ to reach $C_{\text {mopt }}$ (Figs. 2 and 3). This feature is mainly due to the time-dependence of thermal diffusion. As a practical matter, using repetitively pulsed lasers, it is less expensive to generate a given power with small energy and high repetition rate than the reverse.

Figures 3(a) and 3(b) illustrate what is meant by optimum coupling. ${ }^{28,31}$ At the optimum, a rising trend in $C_{\mathrm{m}}$ from vapor formation is just compensated by a declining trend due to increased laser energy required for accelerating plasma. Determining this optimum quantitatively is a complex problem which depends on target material properties and laser pulse parameters. Coupling in the plasma regime is relatively easy to predict for most passive (nonergetic) materials, such as metals and simple plastics like epoxies. Note that we need to predict not only the magnitude of $C_{\mathrm{m}}$ but

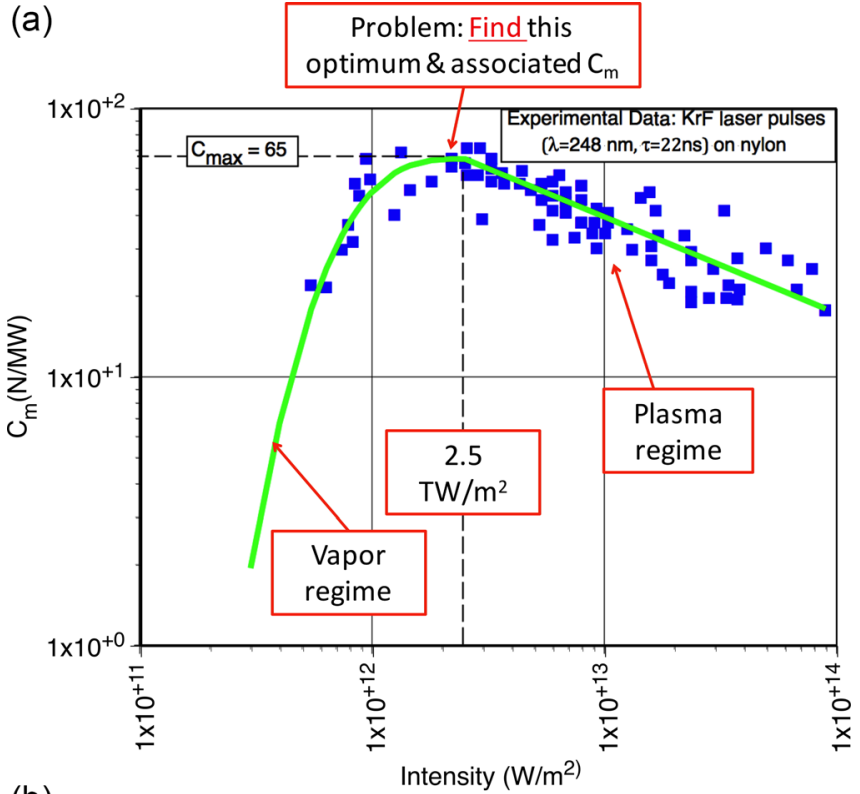

(b)

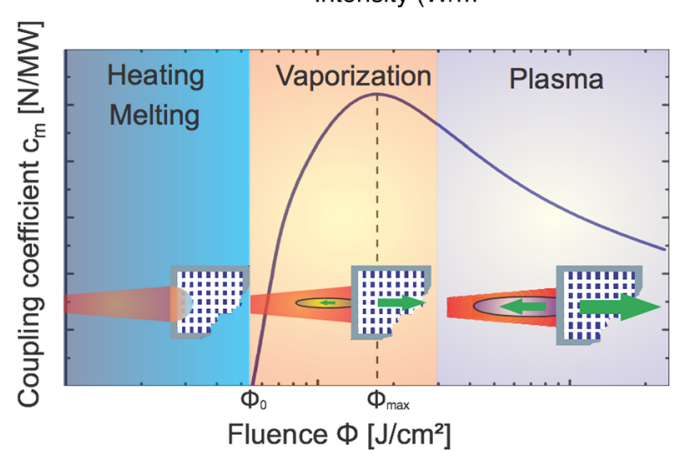

FIG. 3. (a) Optimum coupling illustration. (b) Optimum coupling concept.

also the fluence at which $C_{\text {mopt }}$ occurs. There is a good physical reason for $C_{\mathrm{m}}$ 's decline in the plasma regime: dimensionally, we can see that it varies like $1 / v_{\mathrm{E}}\left(C_{\mathrm{m}}=\mathrm{N}-\mathrm{s} /\right.$ $\mathrm{J}=$ momentum/energy).

\section{Important recent developments in lasers and LAP Applications}

\section{Development of fs fiber laser amplifiers}

Fiber lasers can in principle be combined and phased to provide the average power ( $\mathrm{kW}$ level) and pulse energy $(100 \mathrm{~J})$ necessary for LAP in the $100 \mathrm{~km}$ range $\mathrm{e}^{32-34}$ (the ICAN system). Phasing is a very difficult problem. Considering that pulse energy is limited to about $1 \mathrm{~mJ}$ in fs fibers due to nonlinear optical effects ${ }^{35}$ and that $100 \mathrm{k}$ fibers would be necessary to produce $100 \mathrm{~J}$ pulses, phasing to $\lambda / 10$ would be difficult for CW fibers, let alone fs-pulsed ones. To date, $64 \mathrm{CW}$ fibers ${ }^{36}$ and four fs fibers have been phased. ${ }^{37}$ Nevertheless, if ICAN is successful, many important advantages accrue, particularly light weight, power efficiency, heat dissipation, and near-instantaneous electronic beam steering.

\section{Development of monolithic diode pumped solid state lasers suitable for $L A P$}

In other work, ${ }^{38}$ we have justified the laser requirements shown in Table II. 
TABLE II. Laser requirements.

\begin{tabular}{lc}
\hline \hline Type & Diode-pumped Nd \\
\hline Wavelength & $1057 \mathrm{~nm}$ for ground launch, $532 \mathrm{~nm}$ in space \\
Pulse duration & $80 \mathrm{ps}$ \\
Pulse energy & $0.1-1 \mathrm{~kJ}$ \\
Pulse repetition rate & $250 \mathrm{~Hz}$ \\
Average power & $25-250 \mathrm{~kW}$ \\
\hline \hline
\end{tabular}

Such high repetition rate, high pulse energy lasers are not yet available but are close to being demonstrated. The state of the art in the lasers we currently need to achieve all of these applications is represented in the HiLASE program, ${ }^{39}$ where the Rutherford Appleton Laboratory's "DiPOLE 100" laser achieved its full design performance of $1 \mathrm{~kW}$ average power with $10 \mathrm{~Hz}, 100 \mathrm{~J}$ pulses at $10 \mathrm{~ns}$ pulse duration. We prefer $1057 \mathrm{~nm}$ for the wavelength in atmosphere because absorption is less than that at the second and third harmonics, especially at low elevation angles. In space, $355 \mathrm{~nm}$ is ideal. For energy storage, $6 \mathrm{GJ}, 15 \mathrm{MW}$ super batteries using zinc hybrid cathode technology have now been developed. $^{40}$

\section{Exciting new applications for LAP}

This can expand beyond the initial concepts of space debris removal ${ }^{41,42}$ to spaceborne systems for small debris removal (for which LAP is the only answer) to much more advanced concepts. These include nudging large objects before a predicted collision, reorbiting defunct GEO stations, and launching $25 \mathrm{~kg}$ objects from Earth to low Earth orbit $(\mathrm{LEO})^{43-45}$ and from LEO to interplanetary space. ${ }^{46}$

\section{Important LAP Unknowns}

The leading theory for laser impulse coupling in the plasma regime to passive absorbers like metals and epoxies ${ }^{10}$ breaks down for pulses shorter than $100 \mathrm{ps} .{ }^{47}$ Can we extrapolate from the few measurements valid for longer pulses to the fs and ps regimes? Extrapolation from one simulation ${ }^{26}$ predicted $C_{\mathrm{m}}=100 \mathrm{~N} / \mathrm{MW}$ at $100 \mathrm{ps}^{45}$

What about the "supercouplers," plastics like GAP and polyoxymethylene (POM) which have demonstrated huge coupling coefficients as large as $3000 \mathrm{~N} / \mathrm{MW}$ for ms pulses at $900 \mathrm{~nm}$ and for flights using $10-\mu \mathrm{m}$ lasers ${ }^{48}$ ? None of our extrapolations predict that behavior, and it is currently not understood. Do we get super coupling on POM for $80 \mathrm{ps,}$ $1 \mu \mathrm{m}$ pulses? There is a rumored $10-\mu \mathrm{m}$ resonance, but the same resonance cannot be present at $1 \mu \mathrm{m}$.

What is the thermal coupling coefficient $C_{\mathrm{th}}$ (heat energy deposited in the substrate/incident laser energy) for fs and ps pulses? Our laser launching applications require hundreds of thousands of pulses, and we must have $C_{\mathrm{th}}<=2 \%$ to avoid target melting. Hydrodynamic simulations predict that for ultrashort pulses at $1064 \mathrm{~nm}$, it can be as small as 5\% or even less (see below). This unknown is very important, but not one that we can resolve in this paper. It requires repetitively pulsed short pulse lasers with large pulse energy to resolve. Please see Sec. VIII.

\section{PURPOSE OF THIS WORK}

The purpose of this work was to resolve the unknowns involving $C_{\mathrm{m}}$ in the ps and fs regimes. For this purpose, we required a laser with the order of $10 \mathrm{~J}$ pulse energy and both fs and ps pulse outputs. One of the few in the world capable of this is the "Elfie" facility of École Polytechnique, Palaiseau, France. Fortunately, we obtained two weeks of beam time on Elfie to do this. This is a report of the first round of such experiments.

This facility is capable of $35 \mathrm{TW}, 1057 \mathrm{~nm}$ pulses at 400 fs (better compression), but also $12 \mathrm{~J}$, up to 80 ps pulses (lower compression) by using the chirped, uncompressed pulse shifting from blue to red in its $6 \mathrm{~nm}$ bandwidth. It also operates at the second harmonic, $528 \mathrm{~nm}$, with energy up to $5 \mathrm{~J}$, depending on the compression.

\section{THEORETICAL BACKGROUND}

For laser space propulsion applications, it is critical to know $C_{\mathrm{m}}$, which defines the laser power required to generate a force by ablating the surface of a distant target. $C_{\mathrm{m}}$ varies a lot among materials and with laser parameters. Specific impulse, $I_{\mathrm{sp}}$, gives the lifetime of ablation fuels in laser rocket designs.

Our plasma regime theory was very successful where it applied. ${ }^{10}$ Later work ${ }^{49-51}$ treated the transition from vapordominated to plasma-dominated regimes and permitted estimates $^{52}$ of $C_{\text {mopt }}$ and $\Phi_{\text {opt }}$ using both SESAME tables ${ }^{53}$ and heuristics involving ablation threshold which showed maxima at either 4.2 times $^{50}$ or 6.9 times $^{54}$ the threshold fluence. Obviously, SESAME is better where data exist over a sufficient range of temperatures. In the ns pulse regime, these calculations were quite precise.

\section{A. Fully formed plasma regime theory}

In the fully formed laser produced plasma regime, the plasma itself mediates the laser plasma interaction with a solid surface. The wavelength actually reaching the solid surface will be in the hard UV, independent of the laser wavelength. This is a two-temperature problem with slow and fast ions, the latter being dragged to a high velocity by hot electrons escaping from the laser-produced plasma corona ${ }^{55}$ (Fig. 4). There are good examples for this effect in the literature. ${ }^{56}$ The lower ion temperature is treated in the vapor regime theory.

We assume that the plume velocity distributions are drifting Maxwellians with $\left\langle v_{\mathrm{x}}\right\rangle=u$. Throughout this work, we will use $v_{\mathrm{E}}$ for $\left\langle v_{\mathrm{x}}\right\rangle$.

Then, the $3 \mathrm{D}$ velocity distribution is (where $\beta=m / 2 \mathrm{k} T$ and $\left.\mathrm{C}_{\mathrm{x}}=\mathrm{C}_{\mathrm{y}}=\mathrm{C}_{\mathrm{z}}=(\beta / \pi)^{1 / 2}\right)$

$$
f\left(v_{\mathrm{x}}, v_{\mathrm{y}} v_{\mathrm{z}}\right)=\mathrm{C}_{\mathrm{x}} \mathrm{C}_{\mathrm{y}} \mathrm{C}_{\mathrm{z}} \exp -\beta\left[\left(v_{\mathrm{x}}-u\right)^{2}+v_{\mathrm{y}}^{2}+v_{\mathrm{z}}^{2}\right] .
$$

We have

$$
\begin{aligned}
\left\langle v_{\mathrm{x}}^{2}\right\rangle & =\int \mathrm{d} v_{\mathrm{x}} v_{\mathrm{x}}^{2} f\left(v_{\mathrm{x}}\right)=C_{\mathrm{x}}\left[\pi^{1 / 2} /\left(2 \beta^{3 / 2)+} \pi^{1 / 2} u^{2} / \beta^{1 / 2}\right]\right. \\
& =\left(\mathrm{k} T / m_{\mathrm{E}}+u^{2}\right) .
\end{aligned}
$$




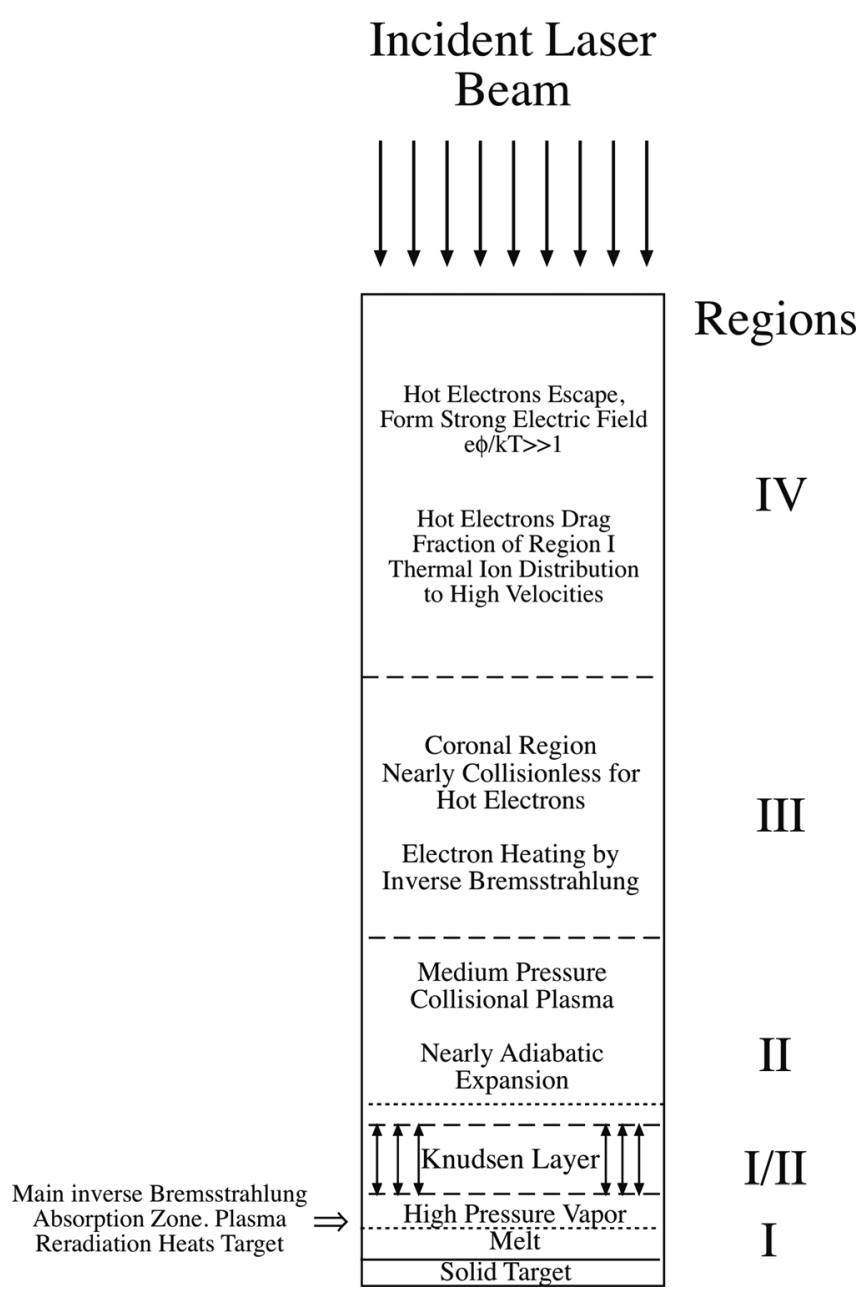

FIG. 4. Four regions of laser plasma interaction.

To gauge the consequence of substituting $\left\langle v_{\mathrm{x}}{ }^{2}\right\rangle$ by $\left(\left\langle v_{\mathrm{x}}\right\rangle\right)^{2}$ in Eq. (3), we calculate their ratio $\psi$ from Eqs. (5) and (6) to find

$$
\Psi=\left(u^{2}+\mathrm{k} T / m_{\mathrm{E}}\right) / u^{2} .
$$

If we consider a Mach $1\left(M=u / c_{\mathrm{s}}=1\right)$ drift velocity with sound speed

$$
\begin{aligned}
& c_{\mathrm{s}}=\left(\gamma \mathrm{k} T / m_{\mathrm{E}}\right) 1 / 2, \quad \text { and } \quad \gamma=C_{\mathrm{p}} / C_{\mathrm{v}}=5 / 3, \\
& \text { we have } \psi=1.60 .
\end{aligned}
$$

However, a preponderance of measurements summarized in the study by Phipps and Dreyfus ${ }^{55}$ shows highly pronounced forward peaking relative to the angular distribution one would obtain with $M=1$. With $\theta$ being the angle to the surface normal, these authors reported a $\cos ^{\nu} \theta$ plume distribution which corresponded to $M=2$. Then, Eq. (7) gives

$$
\psi=(4 \gamma+1) / 4 \gamma=1.15 .
$$

We take $\psi=1$, a slight error that actually underestimates $\eta_{\mathrm{AB}}$, as can be seen in Eq. (3).

It is clear that assigning a single temperature to the plasma plume is not very meaningful. To make the problem tractable, we use decoupled electron and ion temperatures $T_{\mathrm{e}}$ and $T_{\mathrm{i}}$ and make several other assumptions listed in Ref. 10. The salient results are as follows (subscript "p" indicates the plasma regime):

$$
\begin{aligned}
C_{\mathrm{mp}}= & p / I=1.24 \times 10^{-4} \\
& \times\left[A^{7 / 16} Z^{-3 / 8}(Z+1)^{-3 / 16}\left(I \lambda t^{1 / 2}\right)^{-1 / 4}\right] \mathrm{N}-\mathrm{s} / \mathrm{J}, \\
I_{\mathrm{spp}}= & 652\left[Z^{3 / 8}(Z+1)^{3 / 16}\left(I \lambda t^{1 / 2}\right)^{1 / 4} A^{-7 / 16} \mathrm{~s},\right. \\
T_{\mathrm{ep}} & =2980\left[\mathrm{Z}^{3 / 4}(Z+1)^{-5 / 8}\left(I \lambda \tau^{1 / 2}\right)^{1 / 2}\right] \mathrm{K} .
\end{aligned}
$$

In Eqs. (9)-(11), $Z$ is the average charge state of the plasma plume. This is a number which can be as large as the atomic number of the atoms, depending on $T_{\mathrm{ep}} . A$ is the average atomic mass; $I, \lambda$, and $\tau$ are the laser beam intensity $\left(\mathrm{W} / \mathrm{m}^{2}\right)$ on the target, wavelength, and pulse duration, respectively. $I_{\mathrm{sp}}$ is the specific impulse, defined earlier.

These are strictly functions of $\left(I \lambda \tau^{1 / 2}\right)$ and of $A$ and $Z$. Because of plasma shielding, $A$ and $Z$ are the only parameters that relate to the target material in the plasma regime. Reference 10 shows that despite its simplicity, this model represents data from 47 datasets with various wavelengths, intensities, and pulse durations very well. "Bumps" in the data fitting function are due to changing $Z$. Determining $Z$, which also depends upon $I$ through the Saha equation, can be computationally intensive. In the limits of this theory, $C_{\mathrm{m}} I_{\mathrm{sp}}=0.08$, and so, $\eta_{\mathrm{AB}}=40 \%$. It was unexpected that this theory fits data as well as it does.

\section{B. Vapor regime theory}

It is clear that if we can model the vapor regime (left hand side of Fig. 3) and if we can find a smooth transition between the two regimes, then we will have the optimum fluence. The vapor regime clearly involves the detailed target properties. It is here that the second temperature $T=T_{\mathrm{i}}$ comes into play in the combined theory.

There are two approaches to modeling the vapor regime. The first uses tabulated pairs of pressure and temperature $(p, T)$ from SESAME tables for some elements. ${ }^{42,52} \mathrm{By}$ equating laser intensity to energy sinks in the vapor regime, we obtain

$$
\begin{aligned}
I= & (p v / a)[\gamma /(\gamma-1)]\left[1-T_{\mathrm{o}} / T+q /\left(C_{\mathrm{p}} T\right)\right. \\
& +(\gamma-1) / 2)]+(\sigma \varepsilon / a) T^{4}+f(T),
\end{aligned}
$$

where $f(T)=\left\{\phi\left(T, x_{\mathrm{h}}\right)+\left[x_{\mathrm{h}} \rho_{\mathrm{s}} C_{\mathrm{v}}\left(T-T_{\mathrm{o}}\right)\right] / \tau\right\} / a$.

In Eq. (12), $a$ is the total absorption fraction of the target (not absorption coefficient), $\sigma$ is the Stefan-Boltzmann constant, $\varepsilon$ is emissivity, and $\phi$ is a flux limiter from inertial confinement fusion theory. We can relate the quantity $p$ in Eq. (12) to $T$ by using the Riedel equation ${ }^{57}$ in conjunction with the SESAME equation-of-state database (e.g., for aluminum) maintained at Los Alamos National Laboratory for $T \leq 7890 \mathrm{~K}$, its triple point.

Equations (12) and (13) are wavelength-dependent insofar as $\lambda$ affects the surface absorptivity $a$. Of course, temperature $T$ also affects $a$, so these relationships are recursive. 
For the infrared to ultraviolet range studied here, we used $0.05 \leq a \leq 0.24$ for modeling aluminum. ${ }^{52}$

We now have a numerical solution which relates $p_{\mathrm{v}}$ and $v$ to $I$ over the range corresponding to our $p(T)$ data and can then compute the vapor regime coupling coefficient as

$$
C_{\mathrm{mv}}=p_{\mathrm{v}} / I \text {. }
$$

A second approach is used where ablation threshold $\Phi_{\mathrm{o}}$ is well-defined but the $(\mathrm{p}, \mathrm{T})$ pairs are not available. ${ }^{50}$ In this case, where $\xi=\Phi / \Phi_{\mathrm{o}}, \alpha$ (absorption coefficient, $\mathrm{m}^{-1}$ ) is different from $a$ (fraction absorbed).

$$
\begin{gathered}
C_{\mathrm{mv}}=\left[2 \rho C^{2}(\xi-1) \ln \xi /\left(a \Phi_{\mathrm{o}} \xi^{2}\right)\right]^{1 / 2} \text { and } \\
I_{\mathrm{spv}}=\left[2 \alpha \Phi_{\mathrm{o}}(\xi-1) /\left(\rho \mathrm{g}_{\mathrm{o}}^{2} \ln \xi\right)\right]^{1 / 2}
\end{gathered}
$$

$C$ is a free parameter derived by matching ablated mass density data to the expression

$$
\mu=(\rho / \alpha) \ln (C \xi) \quad \mathrm{kg} / \mathrm{m}^{2} .
$$

The $C_{\mathrm{mv}} I_{\mathrm{spv}}$ product from Eqs. (15) and (16) gives $\eta_{\mathrm{AB}}=\left(\mathrm{g}_{\mathrm{o}} / 2\right)$ $C_{\mathrm{mv}} I_{\mathrm{spv}}=\left(2 C / \mathrm{g}_{\mathrm{o}}\right)(1-1 / \xi)$, a function which approaches 1 asymptotically. The coupling coefficient in Eq. (15) maximizes at $\Phi_{\text {opt }}=4.2 \Phi_{\mathrm{o}}$.

\section{Combined theory}

To make a smooth transition between the vapor and plasma models, we use the ionization fraction $\eta_{\mathrm{i}}$ as a weighting function to combine the two models, attenuating the vapor contribution to zero as ionization becomes complete,

$$
C_{\mathrm{m}}=p / I=\left[\left(1-\eta_{\mathrm{i}}\right) p_{\mathrm{v}}+\eta_{\mathrm{i}} p_{\mathrm{p}}\right] / I=\left(1-\eta_{\mathrm{i}}\right) C_{\mathrm{mv}}+\eta_{\mathrm{i}} C_{\mathrm{mp}} .
$$

Combined theory specific impulse can be obtained in the same way. The combination has yielded good fitting of actual coupling data, ${ }^{52}$ including the $\mathrm{C}_{\text {mopt }}$ peak. An example is shown in Fig. 5, from Photonic Associates' CLAUSIUS code, an example which shows that real optimum intensities are well represented. Note that $\eta_{\mathrm{i}} \neq Z$.

Efforts ${ }^{44,45}$ to extrapolate $\Phi_{\text {mopt }}$ and $C_{\text {mopt }}$ across ranges of wavelength and pulse duration, relying on existing simulation results and without doing these calculations, were not successful.

$C_{\mathrm{m}}$, the ratio of impulse to incident laser energy or thrust to power in laser ablation, can be written in several ways,

$$
C_{\mathrm{m}}=m_{\mathrm{T}} \delta v_{\mathrm{T}} / W=\delta \mu_{\mathrm{E}} v_{\mathrm{E}} / \Phi=F / P=J / W,
$$

with dimensions $\mathrm{N}-\mathrm{s} / \mathrm{J}$ or $\mathrm{N} / \mathrm{W}$. We will also quote $C_{\mathrm{m}}$ in units of N/MW, for convenience. In Eq. (19), $m_{\mathrm{T}}$ is the target mass, $\delta v_{\mathrm{T}}$ is the change in target velocity, $W$ is the pulse energy, $J$ is the impulse (N-s), $p$ is the surface pressure at the target, $I$ is the intensity $\left(\mathrm{W} / \mathrm{m}^{2}\right), \Phi=I \tau$ is the fluence on the target $\left(\mathrm{J} / \mathrm{m}^{2}\right), v_{\mathrm{E}}$ is the exhaust velocity of the laser ablation jet, and $\delta \mu_{\mathrm{E}}$ is the areal mass density $\left(\mathrm{kg} / \mathrm{m}^{2}\right)$ in the ablation jet column created by one pulse. The change in velocity of the propelled target from a single pulse is

$$
\begin{gathered}
\delta v_{\mathrm{T}}=C_{\mathrm{m}} \Phi / \mu_{\mathrm{T}}, \\
\text { and } \delta v_{\mathrm{T} \|}=\eta_{\mathrm{c}} \delta v_{\mathrm{T}} .
\end{gathered}
$$

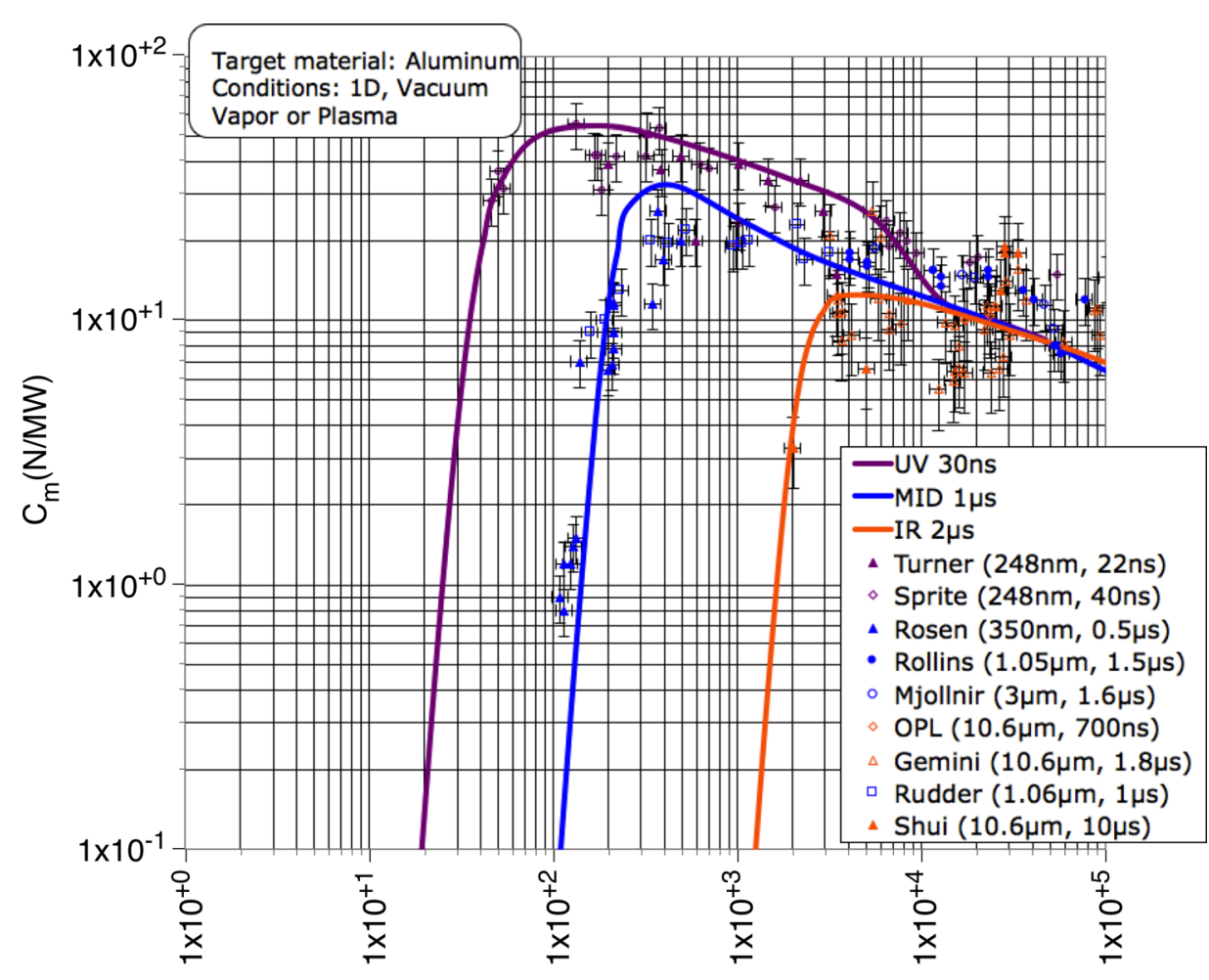

Parameter $\mathrm{I} \lambda \tau^{1 / 2}\left(\mathrm{~W} / \mathrm{m}-\mathrm{s}^{1 / 2}\right)$
FIG. 5. Combined Theory. Sources are identified in Ref. 52. 
In Eqs. (20) and (21), $\mu_{\mathrm{T}}$ is the target's areal mass density $\left(\mathrm{kg} / \mathrm{m}^{2}\right)$ and $\eta_{\mathrm{c}}$ is an average geometrical efficiency factor taking account of the shape of the target and the fact that the ablation jet will be normal to each facet of its surface, not necessarily antiparallel to the laser beam. The quantity $\delta v_{\mathrm{T} \|}$ is the change in target velocity parallel to the beam. Equations (20)-(21) are a numerically convenient formulation for space applications because we can deliver a fluence $\Phi$ to any object within the illumination diameter having mass density $\mu_{\mathrm{T}}$ and the same $\eta_{\mathrm{c}}$ and be sure that it will gain the same velocity increment from that pulse. Space debris tends to exist in families with similar $\mu_{\mathrm{T}}$. For direct comparison to electric propulsion engines, the thrust to electrical power ratio is

$$
C_{\mathrm{me}}=\eta_{\mathrm{eo}} C_{\mathrm{m}} .
$$

Laser electrical-to-optical efficiency $\eta_{\mathrm{eo}}$ can range from 25 to $80 \%$, depending on the laser type. Exhaust velocity can be determined from the product of the easily measured quantities $C_{\mathrm{m}}$ and Q (J/kg ablated) as follows. Here,

$$
Q=W / \delta m_{\mathrm{T}}=\Phi / \delta \mu_{\mathrm{T}},
$$

and because $\delta \mu_{\mathrm{T}}=\delta \mu_{\mathrm{E}}$ by mass conservation, it can be seen dimensionally that the product $C_{\mathrm{m}} Q$ is a typical velocity in the ablation jet

$$
v_{\mathrm{E}}=C_{\mathrm{m}} Q .
$$

Ablation thrust efficiency is given by

$$
\eta_{\mathrm{AB}=} \delta \mu_{\mathrm{E}} v_{\mathrm{E}}^{2} /(2 \Phi)=C_{\mathrm{m}} v_{\mathrm{E}} / 2=C_{\mathrm{m}} I_{\mathrm{sp}} \mathrm{g}_{\mathrm{o}} / 2 .
$$

In Eq. (25), $g_{\mathrm{o}}$ is the acceleration of gravity. Equation (25) makes it clear that $C_{\mathrm{m}}$ and $I_{\mathrm{sp}}$ are a constant product in which $I_{\mathrm{sp}}$ varies inversely with $C_{\mathrm{m}}$ for engines with the same efficiency. The parameter $Q(\mathrm{~J} / \mathrm{kg}$ ablated) is critical to determining $\eta_{\mathrm{AB}}$, which governs the effectiveness of a particular laser and laser ablation fuel. In principle, one may measure $v_{\mathrm{E}}$ with streak photography or Faraday probes to determine $Q=v_{\mathrm{E}} / C_{\mathrm{m}}$, but it is easy to miss a large mass fraction moving at very low velocity (splashing) with this method. Considering the difficulty of measuring ablated material mass with microgram accuracy from before-and-after target mass measurements, the most direct method to determine $Q$ is from

$$
Q=\Phi /\left(\rho_{\mathrm{T}} \delta x\right)=2 \eta_{\mathrm{AB}} / C_{\mathrm{m}}^{2}
$$

by measuring the average depth $\delta x$ of the ablation crater with profilometry or a similar technique.

The units of $I_{\mathrm{sp}}$ are seconds. Another constant product

$$
C_{\mathrm{m}}^{2} Q=2 \eta_{\mathrm{AB}}
$$

defines the ablation efficiency $\eta_{\mathrm{AB}}$. Because $\delta \mu_{T}=\rho_{T} \delta x$, using Eqs. (19) and (25), the thickness of the target layer ablated in one pulse is

$$
\delta x=C_{m} \Phi /\left(2 \rho_{\mathrm{T}} \eta_{\mathrm{AB}}\right) .
$$

For example, with an aluminum target (density $\rho_{\mathrm{T}}$ $\left.=2700 \mathrm{~kg} / \mathrm{m}^{3}\right)$, if $C_{\mathrm{m}}=30 \mathrm{~N} / \mathrm{MW}, \Phi=30 \mathrm{~kJ} / \mathrm{m}^{2}$, and $\eta_{\mathrm{AB}}$ $=1, \delta x=5 \mathrm{~nm}$. At a pulse repetition frequency $f=50 \mathrm{~Hz}$, the total ablation depth is $\delta x_{\text {tot }}=15 \mu \mathrm{m}$ per minute. The ablated surface can be quite uniform, using a beam created with modern methods of apodization.

\section{Optima}

For each mission, there is a different kind of optimum from the $C_{\text {mopt }}$ giving maximum mechanical coupling. This optimum, $C_{\text {mopt-Ms }}$, gives minimum energy cost to complete the mission. For example, for one Earth to LEO mission simulation, $C_{\text {mopt-MS }}$ was $200-500 \mathrm{~N} / \mathrm{MW}^{43}$ (Fig. 6). In the figure, we see that in this simulation, $C_{\mathrm{m}}=1000 \mathrm{~N} / \mathrm{MW}$ has an infinite cost for a $200 \mathrm{~s}$ flight (dot at the top). Yet another $C_{\mathrm{m}}$ optimum is the one that delivers the highest mass ratio $m / M$ to orbit for LEO launch. This choice corresponds to choosing maximum $I_{\mathrm{sp}}$ and also to increased laser power for flights opposing gravity or those which require rapid acceleration.

\section{EXPERIMENTS}

\section{A. Impulse pendulum measurements}

In order to determine $C_{\mathrm{m}}$, we need laser energy $W$ on the target and impulse $J$ delivered to it. $J$ can be measured using deflection of a pendulum,

$$
J=m_{\text {eff }}\left\{2 g_{\mathrm{o}} L[(1-\cos (\beta / 2)]\}^{1 / 2} .\right.
$$

In Eq. (29), $L$ is the distance from the pendulum fulcrum to the point where laser impulse is generated. $\beta$ is the maximum deflection angle of a probe beam reflected from a mirror attached to the pendulum, which is twice the pendulum deflection angle $\theta$. The period of a pendulum depends only on $g_{\mathrm{o}}$ and $L$, not on the mass, so that it cannot be used to get impulse $J$.

One can also use the powerful "photonic Doppler velocimetry (PDV)" twin-laser technique (see Sec. IV B) to get

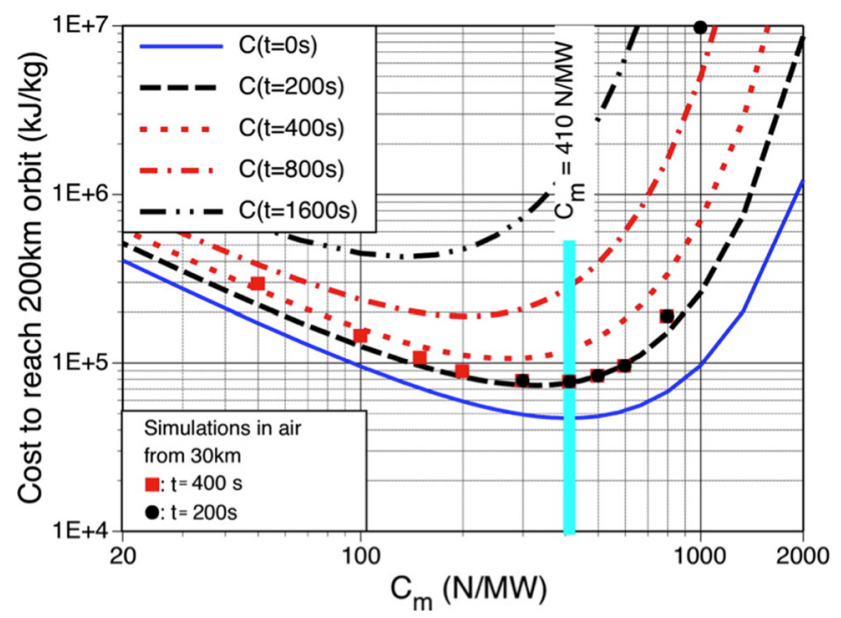

FIG. 6. Each mission has an optimum mission cost impulse coupling coefficient. In this case, a $1 \mathrm{MW}$ average power laser launch from $35 \mathrm{~km}$ to LEO, $C_{\text {mopt-MS }}$, is $300-500 \mathrm{~N} / \mathrm{MW}$ for a $200 \mathrm{~s}$ flight. Lines represent theory and dots denote simulations for a real atmosphere (Adapted from Ref. 43). Optima depend on laser power. 


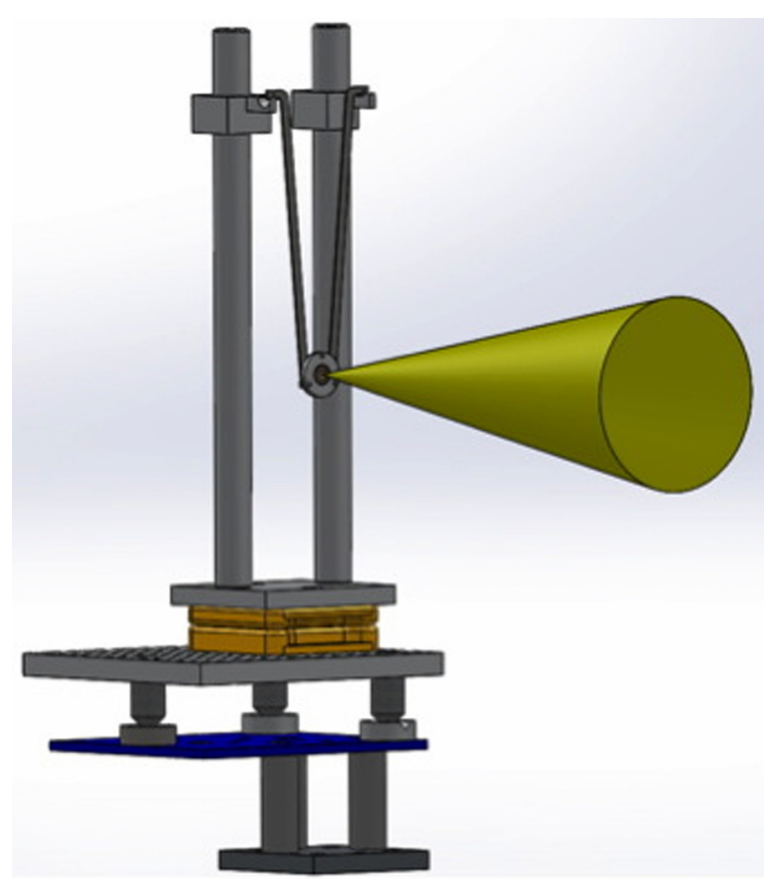

FIG. 7. LULI pendulum. The cone indicates the laser beam.

velocity directly. We used both in this measurement series. In either case, the effective mass $m_{\text {eff }}$ of the target-plus-pendulum must be known

$$
m_{\text {eff }}=\sum_{\mathrm{i}}\left(m_{\mathrm{i}} L_{\mathrm{i}}\right) / L .
$$

Because zero mass pendula do not exist, $m_{\mathrm{eff}}$ is a crucial parameter determining impulse from pendulum measurements. In our measurements, with a $0.0191 \mathrm{~kg}$ pendulum assembly (Fig. 7) and a $0.0038 \mathrm{~kg}$ target mounted, the effective mass was $0.0153 \mathrm{~kg}$, about $80 \%$ of the pendulum assembly total mass of 0.01909 . $L$ was $0.0148 \mathrm{~m}$.

\section{B. Laser velocimetry}

Laser velocimetry is one of the principal diagnostics for shock physics experiments. Historically, two methods have been traditionally used for measuring velocities in the $\mathrm{km} / \mathrm{s}$ range: the VISAR system (Velocity Interferometer System for Any Reflector ${ }^{58}$ and the Fabry-Pérot system. ${ }^{59}$ A new

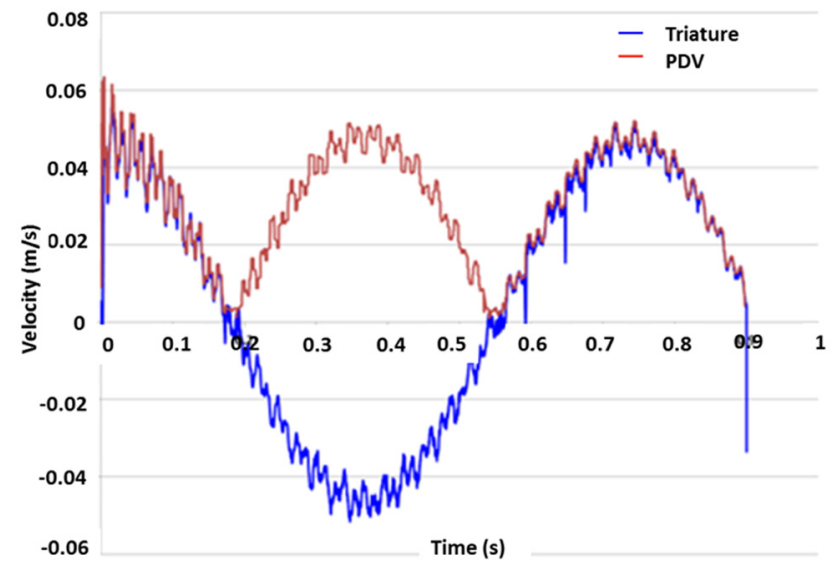

FIG. 9. $v(t)$ curves deduced from PDV (red) and IDF (blue) on shot 48 on the POM target].

method called PDV (Photonic Doppler Velocimetry) based on heterodyne detection is now used to measure the velocity of the matter under shock or of a flying object. ${ }^{60,61}$ This method may be used with one or two lasers. For our application, we use only one laser, due to the problem of laser coherences of the two different lasers for very low velocities and associated high time recording. We used an adaptation of the classical PDV diagnostic (Fig. 8) with two methods to deduce the velocity or displacement curves. ${ }^{62}$ For the classical PDV system, we deduce the $v(t)$ curve by a Fourier transform method without velocity sign. With the triature method IDF (Interferométrie de Déplacement Fibrée), we may deduce the $v(t)$ curve with its associated sign from an analytical formula applied on the three PDV signals. An example of experimental result is given in Fig. 9.

\section{Laser}

The "Elfie" laser at LULI, the Laboratoire pour l'Utilisation des Lasers Intenses at École Polytechnique, uses the CPA technique and can operate at $1057 \mathrm{~nm}(1 \omega)$ as well as $528 \mathrm{~nm}(2 \omega)$ (Table III). At $1 \omega$, energy ranges up to $12 \mathrm{~J}$ on the target with a repetition interval of $20 \mathrm{~min}$. The contrast ratio (ratio between pulse and prepulse intensity) is better than $10^{7}$. At $2 \omega$ and $400 \mathrm{fs}$, the ELFIE laser offers $5 \mathrm{~J}$ pulse energy. It also offers the possibility to modulate the pulse duration from 400 fs up to 80 ps by changing the

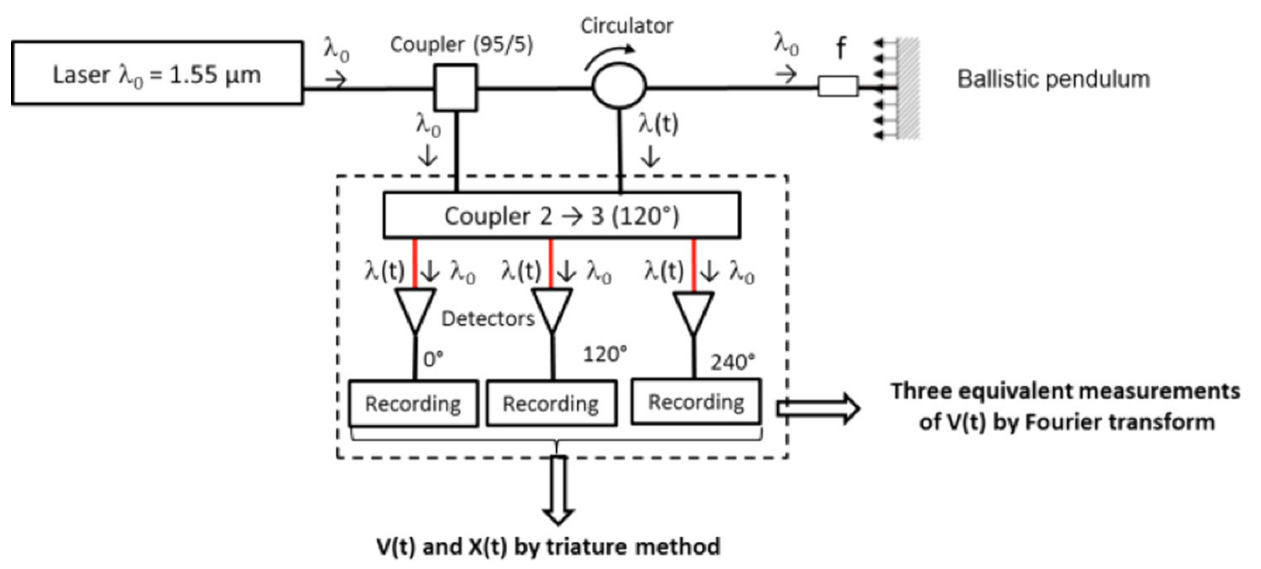

FIG. 8. The experimental setup used to measure the pendulum velocity curve. 
TABLE III. Elfie Laser Parameters.

\begin{tabular}{lcc}
\hline \hline Wavelength & & \\
\hline Pulse duration & $400 \mathrm{fs}$ & $80 \mathrm{~nm}$ \\
Pulse energy $(\mathrm{J})$ & 12 & 12 \\
\hline \hline
\end{tabular}

parameters of the compressor. The experimental setup is shown in Fig. 10.

\section{Practical matters}

In ten days of actual operation for this two-week program, we accumulated 64 shots, about 6/day, limited by the time required to mount a new target, align diagnostics, and to pump down the target chamber for each shot. Statistics on results from such a few shots on many materials are not worthwhile.

We used calibrated neutral density filters to adjust energy on the target. Beam diameters on the target were 3.0 and $6.9 \mathrm{~mm}$ with an extremely uniform laser ablation spot on the target. Pressure was less than 0.1 Torr for all shots. Figure 11 illustrates the illumination uniformity.

\section{Target materials}

We chose POM as a target material out of curiosity, because Myrabo $^{48}$ found it to be a high-thrust material for his "Lightcraft" at $10.6 \mu \mathrm{m}$ wavelength, and we wanted to see if that advantage was transferred to $1.06 \mu \mathrm{m}$.

We chose Al because it is a major spacecraft component, and this work is applicable to propelling objects in space. W and Au were chosen for comparison with the results reported in Ref. 25. Ta was chosen to give a further idea of the variation of $C_{\mathrm{m}}$ with at. wt.

\section{RESULTS}

\section{A. Momentum coupling coefficient}

Figures $12-15$ show the $C_{\mathrm{m}}$ values we obtained vs. incident fluence $\Phi$. For POM and $\mathrm{Al}$ in this short-pulse regime, these are the first measurements in the literature that give a reasonably clear value for the fluence $\Phi_{\text {opt }}$ at which maximum $C_{\mathrm{m}}$ occurs. A word about how we identified "optimum," and its uncertainty is available our data. Where we had enough data to show a clear trend, we chose the fluence at which $C_{\mathrm{m}}$ was a maximum or one at which more fluence could not produce a better result for $C_{\mathrm{m}}$.

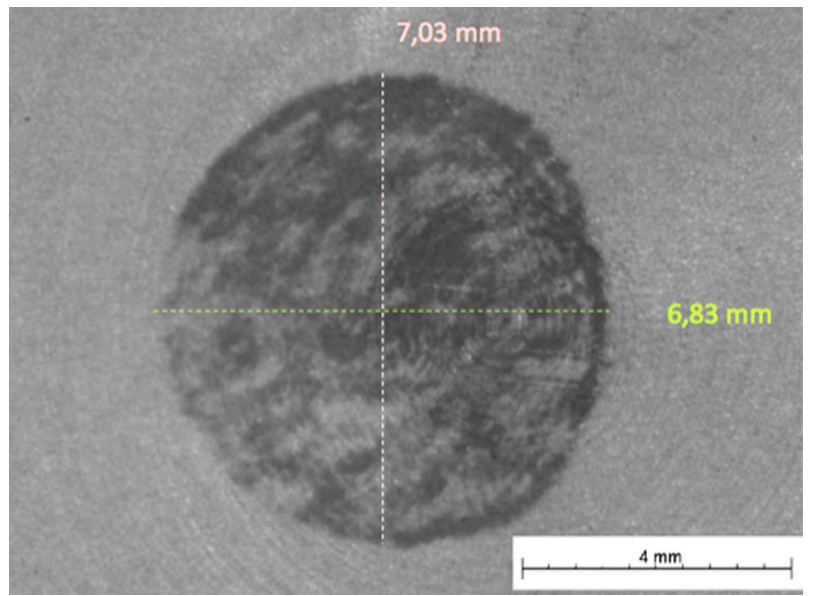

FIG. 11. $0.377 \mathrm{~cm}^{2}$ target illumination spot. Photo of the Delrin (POM) target after metallization with $7 \mathrm{~nm}$ Pt.

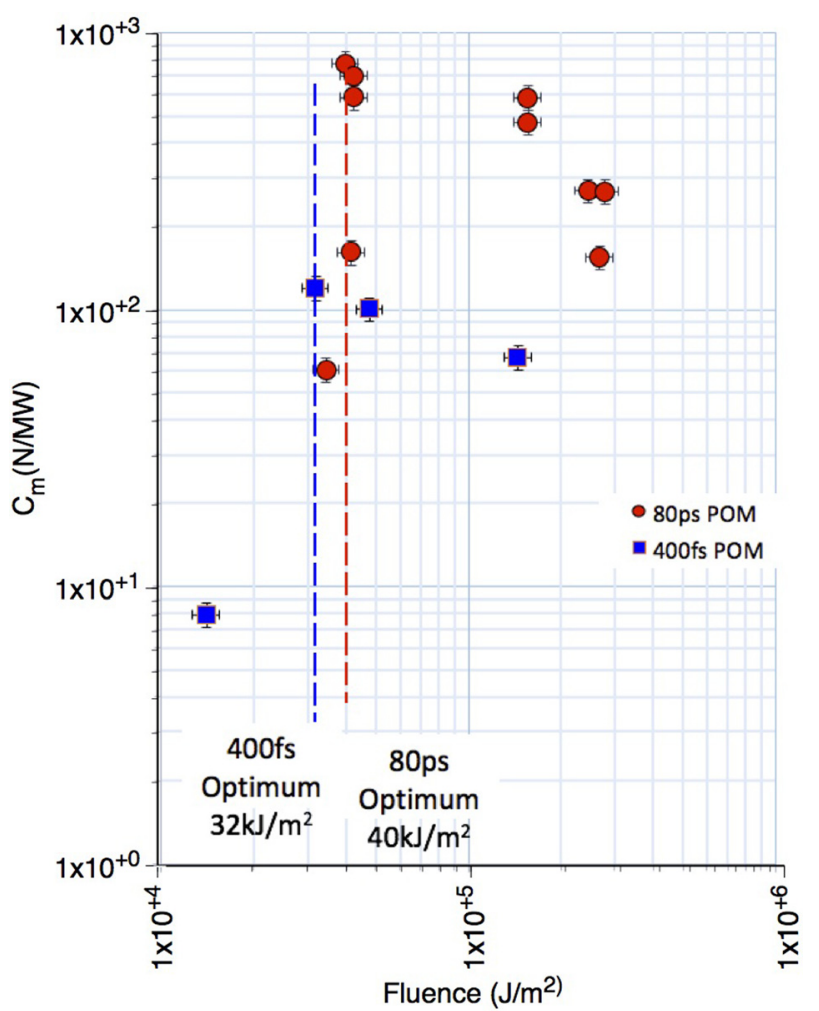

FIG. 12. $C_{\mathrm{m}}$ for POM at $80 \mathrm{ps}$ and $400 \mathrm{fs}, 1057 \mathrm{~nm}$.

In general, our error bars for an individual data point are $\pm 10 \%$ for both fluence and $C_{\mathrm{m}}$. The uncertainty in $C_{m}$

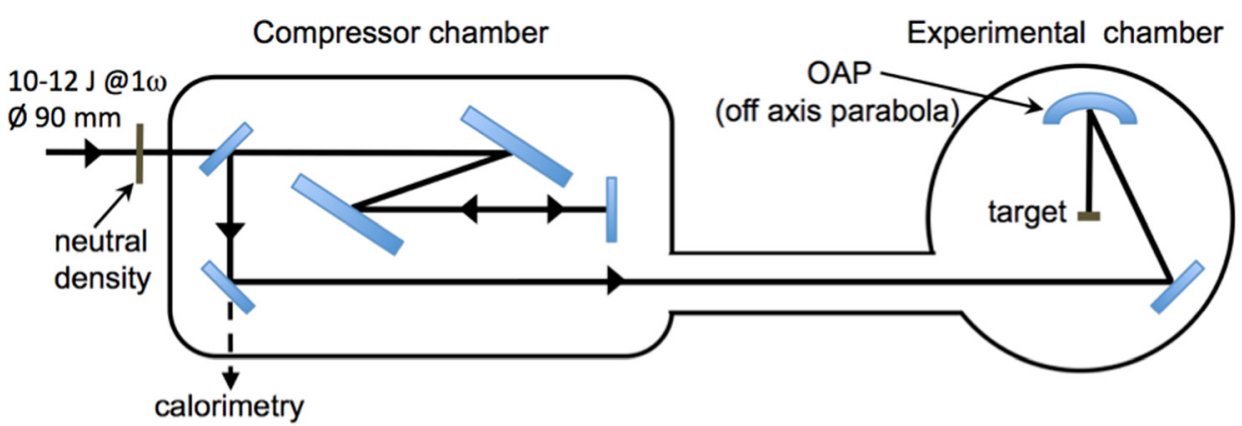

FIG. 10. LULI/Elfie experimental layout. 


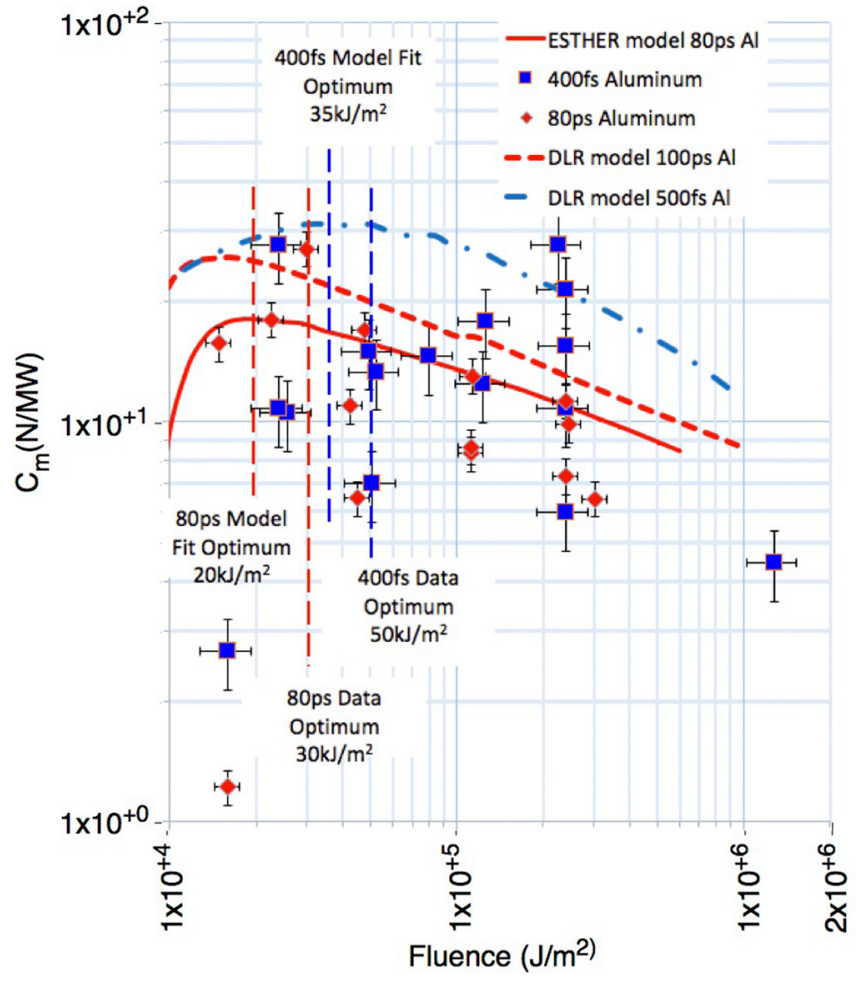

FIG. 13. $C_{\mathrm{m}}$ for aluminum at $100 \mathrm{ps}$ and $400 \mathrm{fs}, 1057 \mathrm{~nm}$. Experimental data compared with simulation results. For the $80 \mathrm{ps}$ data, $\Phi_{\text {opt }}$ is $30 \mathrm{~kJ} / \mathrm{m}^{2}$. For $400 \mathrm{fs}$, we chose $\Phi_{\text {opt }}=50 \mathrm{~kJ} / \mathrm{m}^{2}$ because, as a practical matter, nothing is gained by going to higher fluence. The solid line shows a preliminary modeling using the CEA ESTHER code at $80 \mathrm{ps.} \mathrm{The} \mathrm{dashed} \mathrm{lines} \mathrm{show} \mathrm{simula-}$ tion results from DLR with Polly-2 T for $100 \mathrm{ps}$ and 500 fs pulse durations at $1064 \mathrm{~nm}$ (see Sec. V A for description of these codes).

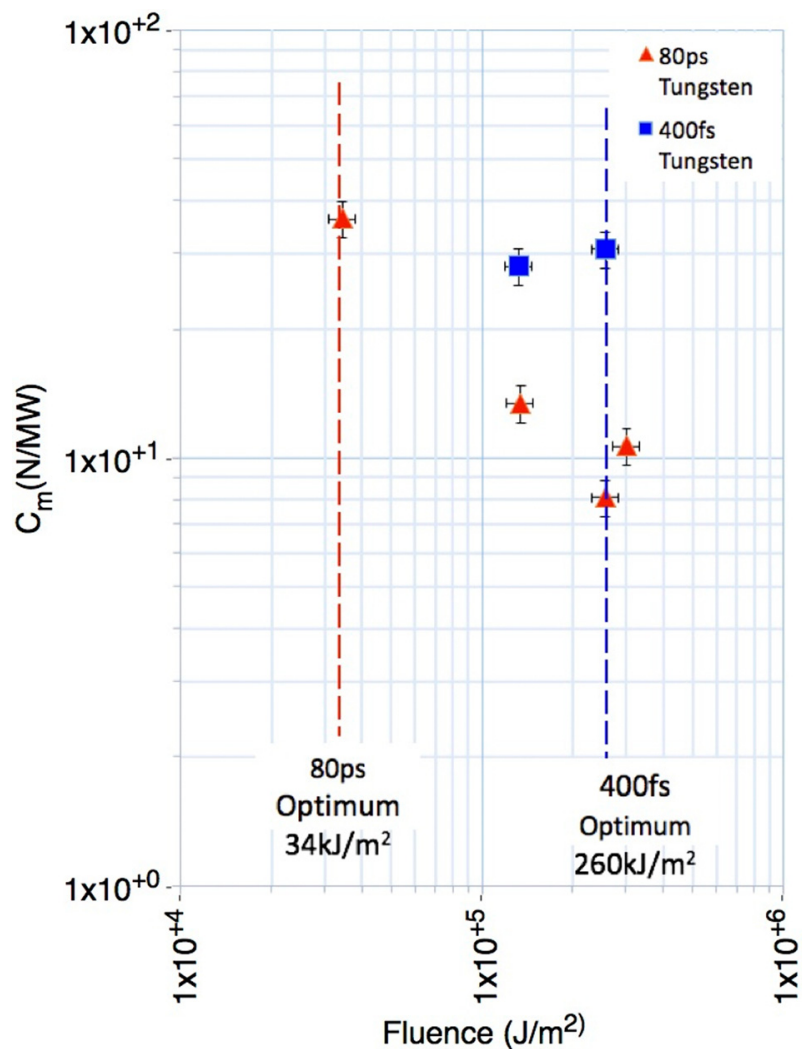

FIG. 14. $C_{\mathrm{m}}$ for $\mathrm{W}$ at $80 \mathrm{ps}$ and $400 \mathrm{fs}, 1057 \mathrm{~nm}$.

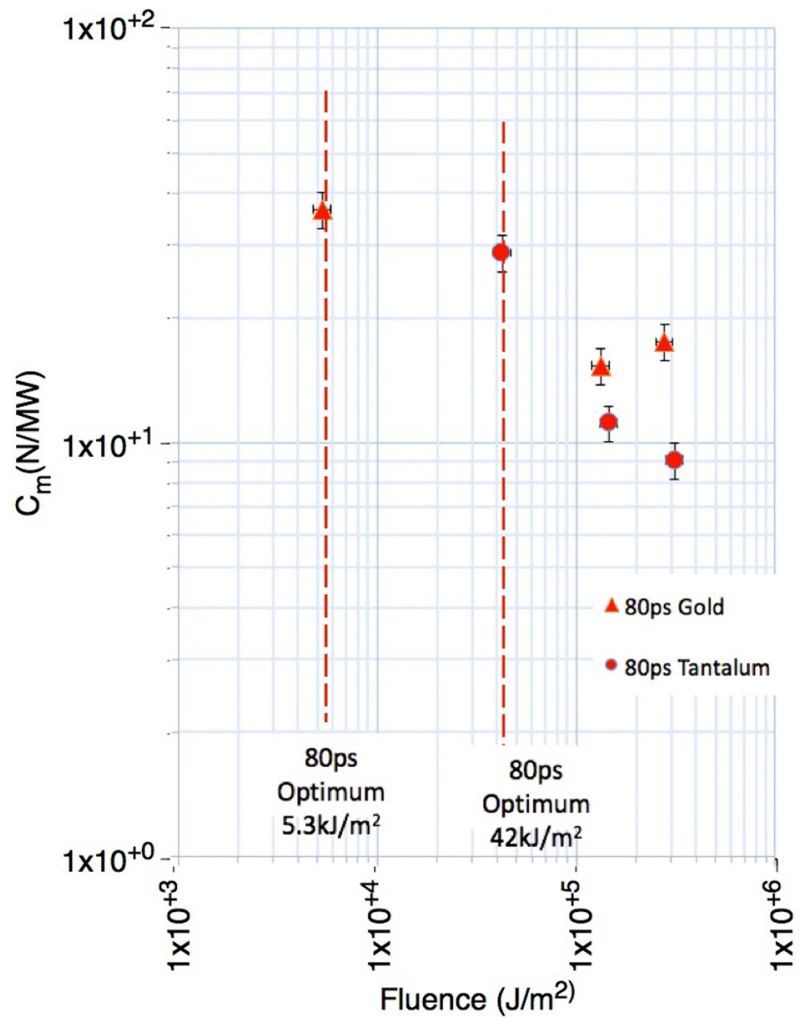

FIG. 15. $C_{\mathrm{m}}$ for $\mathrm{Au}$ and Ta at $80 \mathrm{ps}, 1057 \mathrm{~nm}$. Our aluminum targets were $99.9 \%$ pure, from Goodfellow, Inc.

may have been due to differences in sample preparation. The uncertainty of $\Phi_{\mathrm{opt}}$, particularly where the data show a steep rise or fall in $C_{\mathrm{m}}$ on either side of $\Phi_{\mathrm{opt}}$, is also shown in the table. This uncertainty has less meaning in cases where we had few data (Figs. 14 and 15).

ESTHER $^{62}$ is a Lagrangian monodimensional hydrodynamic code which includes the resolution of the Helmholtz equation which allows us to describe the laser propagation and absorption into the matter. We use a multi-phase equation of state for aluminum. Optical absorption is calculated by using Palik data ${ }^{63}$ when the matter is solid. In the plasma domain, absorption is given by the classical inverse Bremsstrahlung formula. ${ }^{64}$ For aluminum, we also could use hydrodynamic simulations with the code Polly-2 T, described in more detail in the study by Povarnitsyn et al., ${ }^{65}$ to model the two pulse durations. This code is based on the two-temperature model for laser-mater interactions with metal targets ${ }^{66}$ and uses the Helmholtz equation ${ }^{67}$ for coupling laser energy into the target. Semi-empirical equations of state are taken for material description including a dynamic model for dielectric permittivity, electron-phonon coupling, and heat conductivity for a wide range of temperatures. Polly-2 $\mathrm{T}$ was provided by Mikhail Povarnitsyn from the Joint Institute of High Temperatures at the Russian Academy of Sciences, Moscow.

\section{B. Ablated mass measurements}

Tests with both confocal chromatic analysis (CCA, STIL sensor) and scanning electron microscopy analysis (SEM, FEI XL30 ESEM LaB6) were inconclusive regarding ablated mass. The samples were too rough and irregular to permit 


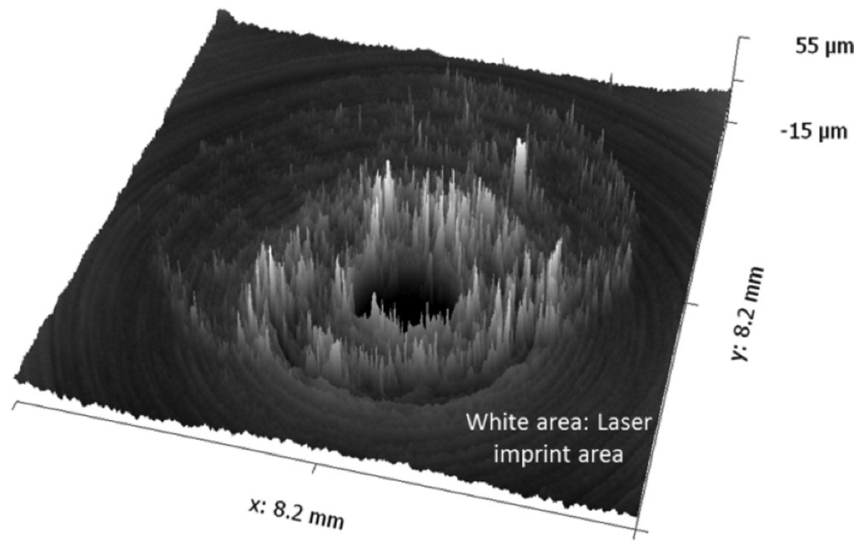

FIG. 16. 3 D representation of the altitude profile on Delrin. Most of the structure we see arises from machining defects.

deduction of ablation depth in the laser illuminated regions (Figs. 16-18).

We note that Eq. (28) gives a predicted ablation depth of at most $770 \mu \mathrm{m}$ for $\mathrm{POM}$ and $31 \mu \mathrm{m}$, respectively, for $\mathrm{Al}$, using $\eta_{\mathrm{AB}}=0.5$ and the maximum values of $C_{\mathrm{m}}$ and $\Phi$ for these materials from Table I, so this result is not surprising.

Table IV gives our results for $\mathrm{Al}$ and $\mathrm{POM}$, with their uncertainties.

\section{DISCUSSION}

Our best estimates of measurement uncertainty are incorporated into the error bars shown in Figs. 12-15. Error bars for $C_{\mathrm{m}}$ and $\Phi_{\mathrm{opt}}$ data for $\mathrm{Al}$ at $400 \mathrm{fs}$ are $\pm 20 \%$ rather than $\pm 10 \%$ in other data. This may be partly due to energy uncertainty early in the 10-day experiment series when the 400 fs data were taken.

Modeling shown in Fig. 13 indicates slightly higher $C_{\mathrm{m}}$ for $\mathrm{Al}$ at $400 \mathrm{fs}$ than at $80 \mathrm{ps}$. Data show a similar trend although scatter makes conclusions tenuous. Both data and modeling show higher $\Phi_{\text {opt }}$ data for $\mathrm{Al}$ at 400 fs than at 80 ps. (a)
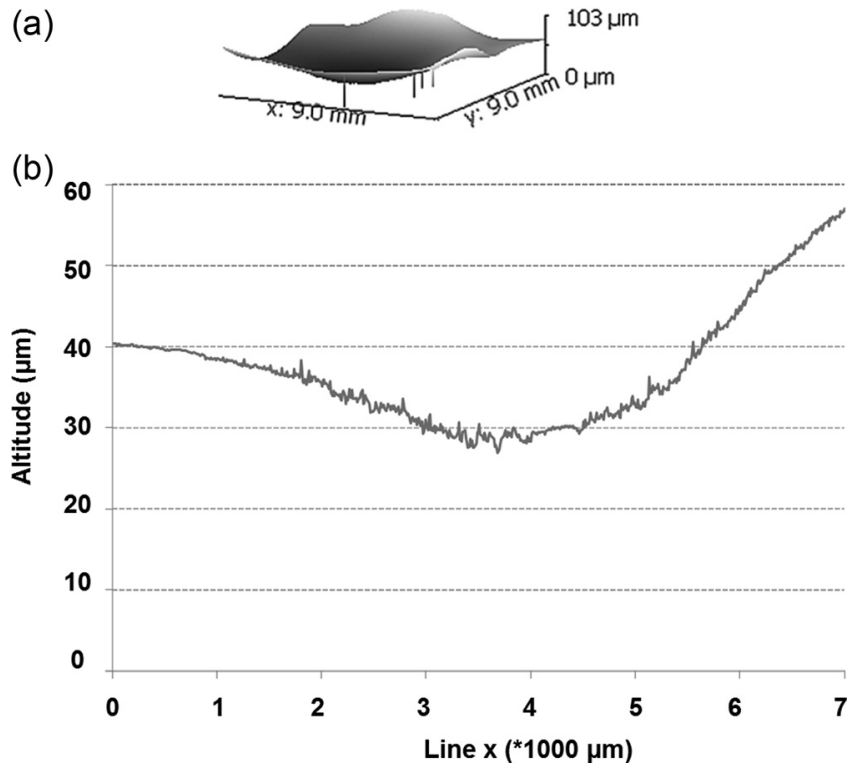

FIG. 18. (a) $3 \mathrm{D}$ representation of an aluminum sample after the shot. (b) Altitude profile of a sample, using CCA. Our measurements gave an inconclusive result for ablation depth.

We find similar $C_{\mathrm{m}}$ values among the metals and not much difference from previous work in the ultrashort range nor from the DLR simulation. ${ }^{27,68}$ for the longer pulses. For POM, we found a gigantic $C_{\mathrm{m}}$ but there is no obvious reason why it should be large at both 1.06 and $10.6 \mu \mathrm{m}$ wavelengths other than its large molecular mass. As to why it should give a factor-of-six smaller result at 400 fs than at $80 \mathrm{ps,}$ ultrashort-pulse $C_{\mathrm{m}}$ should depend primarily on tensile strength, lower $\sigma_{\mathrm{y}}$ giving higher $C_{\mathrm{m}}$. We do see that effect comparing $C_{\mathrm{m}}$ for POM to that for $\mathrm{Al}$ in the $400 \mathrm{fs}$ data (Table V).

For aluminum, the measured coupling coefficient at 80 ps is about three times smaller than the $100 \mathrm{~N} / \mathrm{MW}$ we have assumed at 100 ps for some proposed systems based on LASNEX simulations in Ref. 26. This reference treated
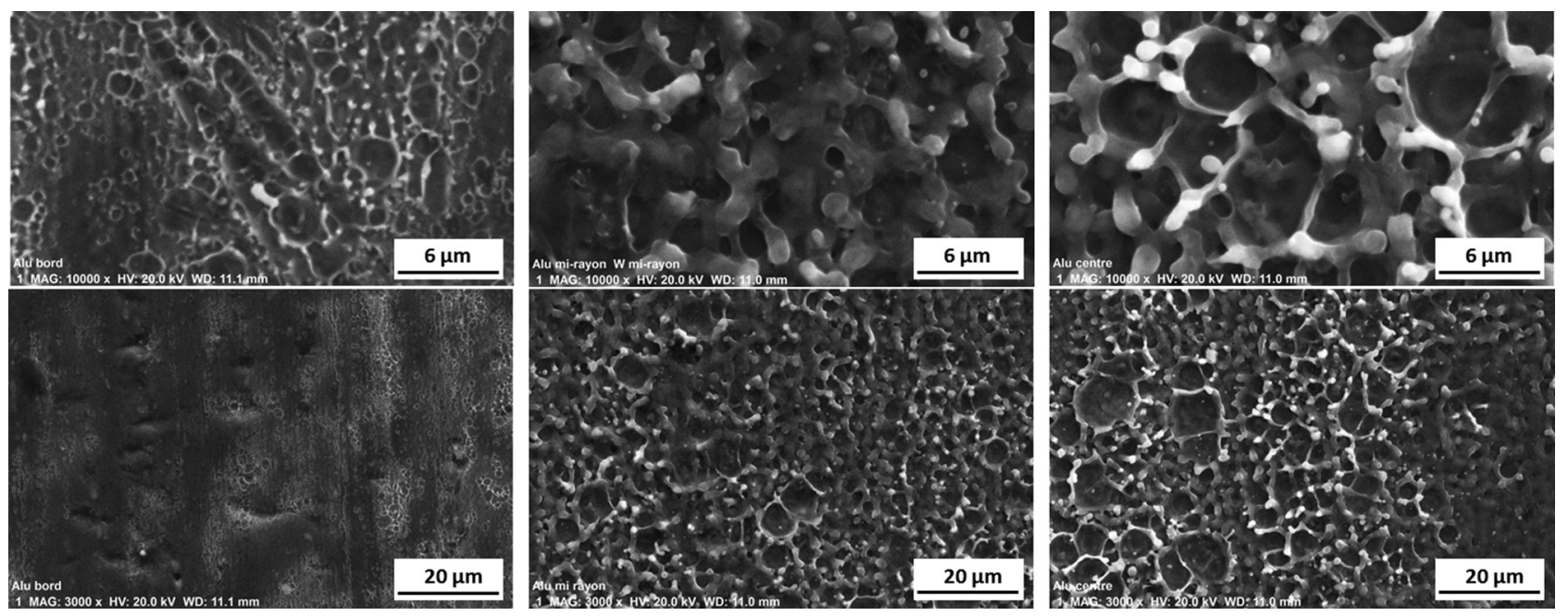

FIG. 17. SEM image of an aluminum sample with magnifications $10 \mathrm{k}$ (top) and $3 \mathrm{k}$ (bottom) at $\Phi=10 \mathrm{~kJ} / \mathrm{m}^{2}$. Left-to-right: unilluminated sample, middle, and center of illumination. We see the characteristic structure of short pulse illumination but no clear boundary that permits the estimation of depth. As regards ablation depth, similar results were obtained with tungsten and tantalum samples and with SEM of Delrin which we metalized with platinum after the shot to make SEM possible. 
TABLE IV. Optimum coupling results for Al and POM at $1057 \mathrm{~nm}$.

\begin{tabular}{|c|c|c|c|c|}
\hline \multirow{2}{*}{$\frac{\text { Material } \rightarrow}{\text { Pulsewidth }}$} & \multicolumn{2}{|c|}{$\mathrm{Al}$} & \multicolumn{2}{|c|}{ POM } \\
\hline & $C_{\mathrm{m}}(\mathrm{N} / \mathrm{MW})$ & $\Phi\left(\mathrm{kJ} / \mathrm{m}^{2}\right)$ & $C_{\mathrm{m}}(\mathrm{N} / \mathrm{MW})$ & $\Phi\left(\mathrm{kJ} / \mathrm{m}^{2}\right)$ \\
\hline $400 \mathrm{fs}$ & $30 \pm 5$ & $50 \pm 10$ & $125 \pm 12$ & $32 \pm 6$ \\
\hline $80 \mathrm{ps}$ & $28 \pm 5$ & $30 \pm 6$ & $773 \pm 70$ & $40 \pm 8$ \\
\hline
\end{tabular}

$530 \mathrm{~nm}$ and $20 \mathrm{ps,}$ while our applications were for $355 \mathrm{~nm}$ and $80 \mathrm{ps}$. Still, this discrepancy is significant. The optimum fluence is four times larger than we assumed previously.

These results are not a severe limitation because higher fluence offsets lower $C_{\mathrm{m}}$ to give the same performance originally claimed for these systems, ${ }^{44,45}$ albeit at the cost of higher laser average power.

On the good side, Eq. (4) shows that when we do deliver the larger $80 \mathrm{ps}$ fluence with much lower $\mathrm{C}_{\mathrm{m}}$, we may expect an aluminum surface to have about twice longer lifetime per laser pulse under optimum irradiation conditions.

Our most pleasant surprise was the performance of POM, which gave an $80 \mathrm{ps} C_{\mathrm{m}}$ value of $773 \mathrm{~N} / \mathrm{MW}$, larger than any other reported unconfined, passive (nonenergetic) material at short pulse durations.

This $C_{\mathrm{m}}$ is too large for most laser launch projects (see Fig. 6), but it is useful from the following point of view: for laser launch projects, using the Table II parameters, we predict that we can cast ablation fuel from a mixture of, e.g., Al dust and POM to obtain $300 \mathrm{~N} / \mathrm{MW}$, or any other value we want in the range from 30 to 770 at 80 ps. The required fluence $\left(\sim 30 \mathrm{~kJ} / \mathrm{m}^{2}\right)$ is about the same for both materials. For reasons having to do with the absence of available laser system designs at $400 \mathrm{fs}$ capable of 100 to $1 \mathrm{~kJ}$ pulses, this pulse duration is presently not attractive compared to $80 \mathrm{ps,} \mathrm{so} \mathrm{it}$ does not concern us that $\mathrm{C}_{\text {mopt }}$ for POM at $400 \mathrm{fs}$ is much less than at $80 \mathrm{ps}$. We can also easily create a fuel with $\mathrm{C}_{\mathrm{m}}=100 \mathrm{~N} / \mathrm{MW}$, as required for Refs. 44 and 45 space system designs. We do expect larger $C_{\mathrm{m}}$ for metal targets at the second and third harmonics (530 and $352 \mathrm{~nm}$ ).

Figure 19 shows how our $C_{\text {mopt }}$ data for aluminum compare with those of other authors at $80 \mathrm{ps}$ and $400 \mathrm{fs}$. Clearly,

TABLE V. New results compared to existing short pulse $\mathrm{C}_{\mathrm{m}}$ data.

\begin{tabular}{lcccc}
\hline \hline Fluence $\left(\mathrm{kJ} / \mathrm{m}^{2}\right)$ & $C_{\text {mopt }}(\mathrm{N} / \mathrm{MW})$ & Pulsewidth & Material & Reference \\
\hline 20 & 18 & $50 \mathrm{fs}$ & $\mathrm{Ti}$ & 23 \\
5.2 & 42 & $130 \mathrm{fs}$ & $\mathrm{Mo}$ & 24 \\
20 & 40 & $130 \mathrm{fs}$ & $\mathrm{W}$ & 25 \\
17 & 85 & $130 \mathrm{fs}$ & $\mathrm{Au}$ & 25 \\
10 & 25 & $130 \mathrm{fs}$ & $\mathrm{Li}$ & 25 \\
13 & 49 & $130 \mathrm{fs}$ & $\mathrm{Fe}$ & 25 \\
13 & 25 & $130 \mathrm{fs}$ & $\mathrm{GAP}$ & 25 \\
12 & 18 & $130 \mathrm{fs}$ & $\mathrm{Al}$ & 25 \\
$30 \pm 20 \%$ & $30 \pm 20 \%$ & $400 \mathrm{fs}$ & $\mathrm{Al}$ & This work \\
$32 \pm 10 \%$ & $120 \pm 10 \%$ & $400 \mathrm{fs}$ & $\mathrm{POM}$ & This work \\
$260 \pm 10 \%$ & $30 \pm 10 \%$ & $400 \mathrm{fs}$ & $\mathrm{W}$ & This work \\
$5.3 \pm 10 \%$ & $37 \pm 10 \%$ & $80 \mathrm{ps}$ & $\mathrm{Au}$ & This work \\
$42 \pm 10 \%$ & $29 \pm 10 \%$ & $80 \mathrm{ps}$ & $\mathrm{Ta}$ & This work \\
$40 \pm 10 \%$ & $780 \pm 10 \%$ & $80 \mathrm{ps}$ & $\mathrm{POM}$ & This work \\
$30 \pm 20 \%$ & $28 \pm 20 \%$ & $80 \mathrm{ps}$ & $\mathrm{Al}$ & This work \\
$36 \pm 10 \%$ & $36 \pm 10 \%$ & $80 \mathrm{ps}$ & $\mathrm{W}$ & This work \\
\hline \hline
\end{tabular}

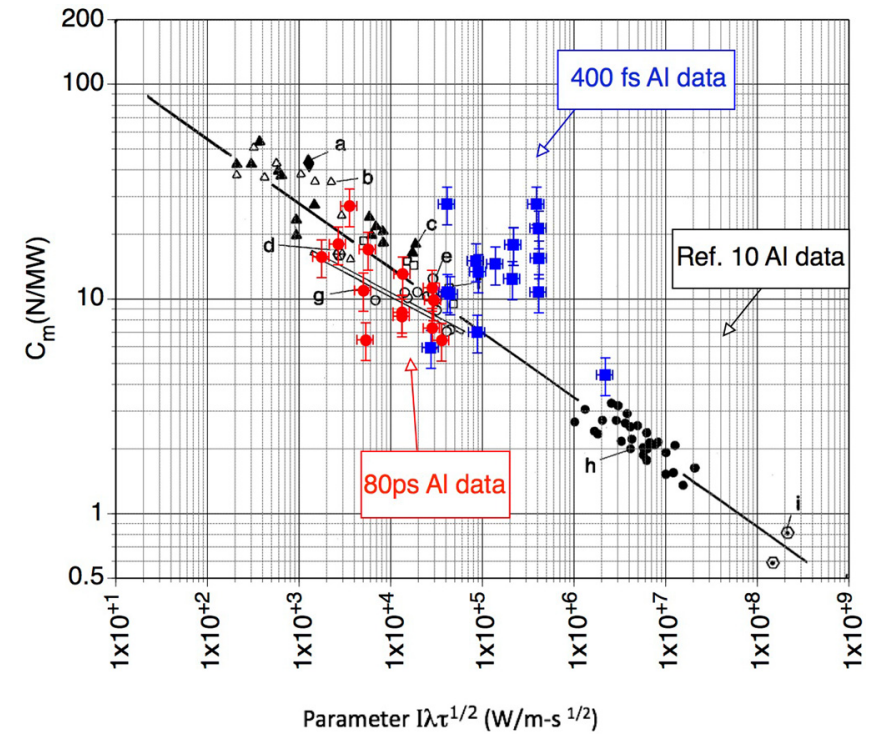

FIG. 19. Our data vs. plasma theory from Ref. 10 and data listed there (grey). The horizontal axis parameter is explained in Sec. III.

there is good agreement at $80 \mathrm{ps}$ and less agreement at $400 \mathrm{fs}$ as expected following the Sec. ID discussion.

At $400 \mathrm{fs}$, it is reasonable for $\mathrm{Au}$ and $\mathrm{Fe}$ to have higher $C_{\mathrm{m}}$ because of their larger at. wt. At $80 \mathrm{ps,} \mathrm{Au} \mathrm{and} \mathrm{W} \mathrm{have}$ larger $C_{\mathrm{m}}$ than $\mathrm{Al}$ and $\mathrm{Ta}$ for the same reason. The limited number of data points for these materials did not permit strong conclusions. As we pointed out earlier, the major influence at 50-400 fs should be a dependence on tensile strength, rather than at. wt., lower $\sigma_{\mathrm{y}}$ giving higher $C_{\mathrm{m}}$. This prediction is approximately borne out. POM performs dramatically at $80 \mathrm{ps}$.

\section{CONCLUSIONS}

For the first time, we have measured the single-pulse mechanical coupling coefficient to POM and some metals at $1057 \mathrm{~nm}, 80 \mathrm{ps}$ and $400 \mathrm{fs}$, and the associated optimum fluences. We found giant $C_{\mathrm{m}}$ results for POM at $80 \mathrm{ps}$, $1057 \mathrm{~nm}$. For Al, there was not much difference from previous work in the ultrashort range nor from Scharring's simulation for the longer pulses. We found a large difference from Fournier's simulation for Al using LASNEX, on which we based some of our past laser propulsion performance extrapolations. We can compensate these by using more laser fluence. We were not able to measure mass loss in this series. We proposed using a cast mixture of $\mathrm{Al}$ dust and POM in varying proportions to obtain $C_{\mathrm{m}}$ values between 30 and 770 N/MW. We intend to buttress this proposal with measurements in the near future.

\section{WHAT IS STILL UNKNOWN}

Two measurements are still urgently needed: the ablation efficiency and thermal coupling coefficients associated with our data. Figure 20 shows an analysis of simulations in Ref. 68 with respect to the residual heat remaining in the target after ablation. The results shown for ultrashort pulses, typically known as "cold ablation," give us hope for the 


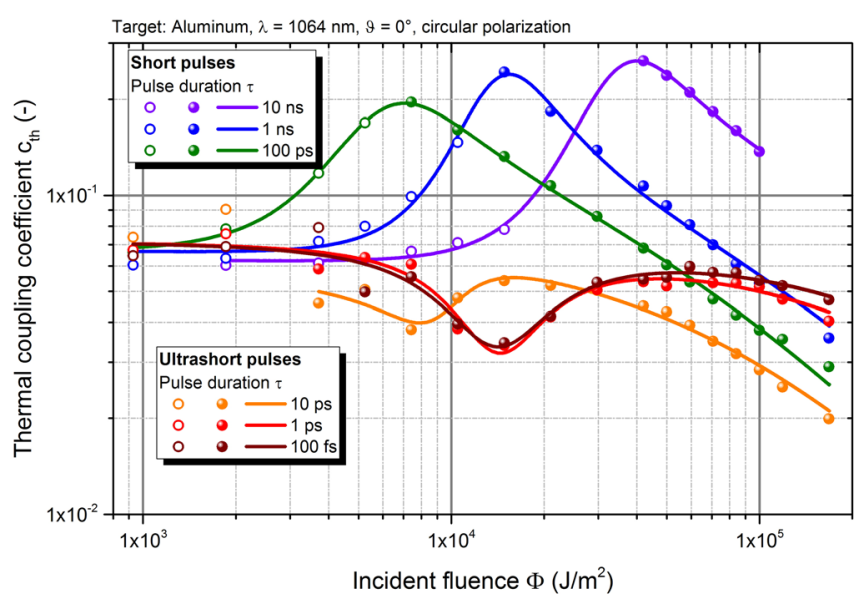

FIG. 20. Numerical simulation of thermal coupling vs. pulse duration and laser fluence on aluminum, including shock thermalization. Full symbols denote ablation, whereas hollow symbols show thermal coupling below ablation threshold.

utility of $1-10$ ps pulses. These should demonstrate $C_{\mathrm{th}}<6 \%$ at $\sim 30 \mathrm{~kJ} / \mathrm{m}^{2}$. However, at fluences above $6 \mathrm{~kJ} / \mathrm{m}^{2}, 10-100$ ps pulses are the best from this crucial viewpoint. Such fluences will be useful when maximum $I_{\mathrm{sp}}$ rather than maximum $C_{\mathrm{m}}$ is the goal (see Sec. IIID). This effect arises because the longer pulses do not add so much thermal coupling from shock.

\section{ACKNOWLEDGMENTS}

We thank the ELFIE technical team for their support before and during the experimental campaign and the LULI Program Committee for having allocated pluri-annual beamtime to our proposal. Aside from the author list, Diona Badarau, Joanna De Sousa, Edouard Veuillot, Pascal Guehennec, and Pierre Untereiner are included. We also thank Alain Burr and Suzanne Jacomet from CEMEF for their help in $3 \mathrm{D}$ confocal chromatic and SEM studies.

This research exploring a new area in Space Science was partly funded by the CNES through Grant No. AVP-CT$0-1603$.

${ }^{1}$ F. Tsander, "Flight to other planets," in Development of Russian Rocket Technology, edited by Ye. Moshkin (Mashinostroyeniye Press, Moscow, 1973) (in Russian).

${ }^{2}$ K. Tsiolkovsky, Plan of Space Exploration, 1926 (in Russian), available in English in Exploration of the Universe with Reaction Machines: Exploring the Unknown, NASA History Series (NASA Washington, D.C., 1995), NASA-SP-4407; available at https://spacemedicineassociation.org/download/history/history_files_1920-1930/Tsiolkovsky\%20Oberth\%20Goddard. pdf.

${ }^{3} \mathrm{H}$. Oberth, Die Rakete zu den Planetenräumen (The Rocket to the Planet Spaces) (Oldenbourg Verlag, München, 1923).

${ }^{4}$ E. Sänger, "Zur theorie der photonenraketen," in Probleme der Weltraumforschung (IVth Internationaler Astronautischer Kongress, Zürich, 1953, Laubscher, Biel-Bienne, 1955), p. 32.

${ }^{5}$ A. Kantrowitz, "Propulsion to orbit by ground-based lasers," Aeronaut. Astronaut. 10(5), 74-76 (1972).

${ }^{6}$ C. R. Phipps, "Pulsed lasers for clearing debris in LEO and GEO," in Optics and Photonics International Conference, Yokohama, 17-20 May 2016, Paper No. LSSE1-1.

${ }^{7}$ Y. Afanas'ev, N. Basov, O. Krokhin, N. Morachevskii, and G. Sklizkov, "Gas-dynamic process in irradiation of solids," Sov. Phys.-Tech. Phys. 14(5), 669-676 (1969).
${ }^{8}$ A. Augustoni, P. Ermer, R. Heckler, G. Kuwashima, J. McKay, and R. Rudder, "The interaction of high energy single pulse XeF laser radiation with solid targets," Report No. AFWL-TR-85-126, U.S. Air Force Research Laboratory, AFB, NM, USA, 1986.

${ }^{9}$ P. Combis, J. David, and G. Nierat, "Mesure des Effets Mécaniques dans les Expériences d'Interaction Laser-Matiere a Eclairement Modéré," in Revue Scientifique et Technique de la Defense, CEL-Valenton No. 4 (Centre des Etudes Limeil-Valenton, Villeneuve-Saint-Georges Cedex, France (1992), pp. 59-75.

${ }^{10}$ C. Phipps, T. Turner, R. Harrison, G. York, W. Osborne, G. Andersson, X. Corlis, L. Haynes, H. Steele, K. Spicochi, and T. King, "Impulse coupling to targets in vacuum by $\mathrm{KrF}, \mathrm{HF}$ and $\mathrm{CO}_{2}$ Lasers," J. Appl. Phys. 64, 1083-1096 (1988).

${ }^{11}$ C. Duzy, J. Woodroffe, J. Hsia, and A. Ballantyne, "Interaction of a pulsed XeF laser with an aluminum surface," Appl. Phys. Lett. 37(6), 542-544 (1980).

${ }^{12}$ J. McKay and P. Laufer, "Survey of laser-produced pressure and impulse data," Physical Sciences, Inc., Final Report No. PSI-1012/TR-757, New England Business Center, Andover, MA, USA, 1987, pp. 1-236.

${ }^{13} \mathrm{D}$. Gregg and S. Thomas, "Momentum transfer produced by focused laser giant pulses," J. Appl. Phys. 37(7), 2787-2789 (1966).

${ }^{14}$ B. Xu, Q. Wang, X. Zhang, S. Zhao, Y. Xia, L. Mei, X. Wang, and G. Wang, "Impulse transfer to the surface of aluminum and copper from a pulsed Nd:YAG laser,” Appl. Phys. B 57, 277-280 (1993).

${ }^{15}$ D. Rosen, D. Hastings, and G. Weyl, "Coupling of pulsed 0.35-mm laser radiation to titanium alloys," J. Appl. Phys. 53(8), 5882-5890 (1982).

${ }^{16}$ D. Rosen, P. Nebolsine, and P. Wu, "Laser impulse applications research," AIAA Conference on Fluid Dynamics of High Power Lasers, Cambridge, MA, 1978, data cited in reference 12, pp. 147-150.

${ }^{17}$ R. Rudder, Report No. AFWL-TR-74-100, U.S. Air Force Research Laboratory, Kirtland Air Force Base, NM, USA, 1974, pp. 189-198.

${ }^{18} \mathrm{~V}$. Shui, L. Young, and J. Reilly, "Impulse transfer from pulsed $\mathrm{CO}_{2}$ laser irradiation at reduced ambient pressures," AIAA J. 16, 649-650 (1978).

${ }^{19}$ I. Ursu, I. Apostol, D. Barbulescu, I. Mihailescu, and M. Moldovan, "Plasma-target coupling in the case of TEA-CO2 laser produced breakdown in front of a solid target," Opt. Commun. 39, 180-185 (1981).

${ }^{20}$ T. Pucik and R. Crawford, "Optical laser impulse coupling data package," RDA Report No. 2.28.90, Logicon/R\&D Associates, Los Angeles, CA, USA, 1990.

${ }^{21}$ B. D'Souza, "Development of impulse measurement techniques for the investigation of transient force due to laser-induced ablation," Ph.D. dissertation (University of Southern California, 2007).

${ }^{22}$ B. Wang, H. Tsuruta, and A. Sasoh, "Impulse generation by multiplepulse laser ablation with oblique incidence," in Proceedings of Laser Solutions for Space and the Earth, Yokohama, 17-20 May 2016, Paper No. LSSE2-4.

${ }^{23}$ E. Loktionov, Y. S. Protasov, and Y. Y. Protasov, "Thermophysical and gas-dynamic characteristics of laser-induced gas-plasma flows under femtosecond laser ablation," Quantum Electron. 44, 225-232 (2014).

${ }^{24}$ C. Phipps, J. Luke, D. Funk, D. Moore, J. Glownia, and T. Lippert, "Measurements of laser impulse coupling at 130fs," Proc. SPIE 5448, 1201-1209 (2004).

${ }^{25}$ C. Phipps, J. Luke, D. Funk, D. Moore, J. Glownia, and T. Lippert, "Laser impulse coupling at 130fs," App. Surf. Sci. 252, 4838-4844 (2006).

${ }^{26} \mathrm{~K}$. Fournier, "LASNEX calculations of laser-coupling coefficients for $\mathrm{Al}$ targets," UCRL-Pres-Report No. 226849, 2006, p. 29.

${ }^{27}$ S. Scharring, J. Wilken, and H.-A. Eckel, "Laser-based removal of irregularly shaped space debris," Opt. Eng. 56, 011007 (2017).

${ }^{28}$ C. R. Phipps, M. Birkan, W. Bohn, H.-A. Eckel, H. Horisawa, T. Lippert, M. Michaelis, Y. Rezunkov, A. Sasoh, W. Schall, S. Scharring, and J. Sinko, "Review: Laser ablation propulsion," J. Propul. Power 26(4), 609-637 (2010).

${ }^{29} \mathrm{C}$. Phipps, Calculations with CLAUSIUS code show Isp $=120$ s with $1.3 \mathrm{GW} / \mathrm{m}^{2} \mathrm{CW}$ laser intensity on $\mathrm{Al}$.

${ }^{30}$ A. Ovsianikov, S. Passinger, R. Houbertz, and B. Chichkov, Laser Ablation and Its Applications (Springer, New York, 2007), Chap. 6, pp. 121-156.

${ }^{31}$ B. Esmiller, C. Jacquelard, H.-A. Eckel, and E. Wnuk, "Space debris removal by ground-based lasers: Main conclusions of the European project CLEANSPACE," Appl. Opt. 53(31), I45-I54 (2014); figure used by Dr. Eckel's permission.

${ }^{32}$ R. Soulard, M. Quinn, T. Tajima, and G. Mourou, "ICAN: A novel laser architecture for space debris removal," Acta Astronaut. 105(1), 192-200 (2014). 
${ }^{33}$ T. Ebisuzaki, M. Quinn, S. Wada, L. Piotrowski, Y. Takizawa, M. Casolino, M. Bertaina, P. Gorodetzky, E. Parizot, T. Tajima, R. Soulard, and G. Mourou, "Demonstration designs for the remediation of space debris from the International Space Station," Acta Astronaut. 112, 102-113 (2015).

${ }^{34}$ L. Daniault, M. Hanna, L. Lombard, Y. Zaouter, E. Mottay, D. Goular, P. Bourdon, F. Druon, and P. Georges, "Coherent beam combining of two femtosecond fiber chirped-pulse amplifiers," Opt. Lett. 36(5), 621-623 (2011).

${ }^{35}$ F. di Teodoro, "Pulsed fiber lasers," in High Power Laser Handbook (McGraw Hill, 2011), Chap. 16, pp. 463-498.

${ }^{36}$ J. Bourdorionnet, C. Bellanger, J. Primot, and A. Brignon, "Collective coherent phase combining of 64 fibers," Opt. Express 19(18), 17053-17059 (2011).

${ }^{37}$ A. Klenke, S. Breitkopf, M. Kienel, T. Gottschall, T. Eidam, S. Hädrich, J. Rothhardt, J. Limpert, and A. Tünnermann, " $530 \mathrm{~W}, 1.3 \mathrm{~mJ}$, four-channel coherently combined femtosecond laser chirped-pulse amplification system," Opt. Lett. 38(13), 2283-2285 (2013).

${ }^{38}$ C. Phipps, C. Bonnal, F. Masson, M. Boustie, L. Berthe, S. Baton, E. Brambrink, J.-M. Chevalier, L. Videau, S. Boyer, and M. Schneider, "Small payload transfers from earth to LEO and LEO to interplanetary space using lasers," in Proceedings of 7th European Conference for Aeronautics and Space Sciences, Milan (2017), Paper No. 679.

${ }^{39} \mathrm{See}$ http://www.hilase.cz/en/advanced-dpssl-laser-dipole-100-delivers-1 kwperformance/ for first report of $1 \mathrm{~kW}$ average power in $100 \mathrm{~J}$, ns-duration pulses at $10 \mathrm{~Hz}$.

${ }^{40}$ See https://eosenergystorage.com/products-technology/ for high energy density ZNYTH Zinc Hybrid Cathode Technology.

${ }^{41}$ C. Phipps, G. Albrecht, H. Friedman, D. Gavel, E. George, J. Murray, C. Ho, W. Priedhorsky, M. Michaelis, and J. Reilly, "ORION: Clearing nearEarth space debris using a $20 \mathrm{~kW}, 530 \mathrm{~nm}$, Earth-based, repetitively pulsed laser," Laser Part. Beams 14(1), 1-44 (1996).

${ }^{42}$ C. Phipps, K. Baker, S. Libby, D. Liedahl, S. Olivier, L. Pleasance, A. Rubenchik, J. Trebes, E. George, B. Marcovici, J. Reilly, and M. Valley, "Removing orbital debris with lasers," Adv. Space Res. 49, 1283-1300 (2012).

${ }^{43}$ C. Phipps, J. Reilly, and J. Campbell, "Optimum parameters for laserlaunching objects into low Earth orbit,” Laser Part. Beams 18(4), 661-695 (2000).

${ }^{44}$ C. R. Phipps, "L'ADROIT-A spaceborne ultraviolet laser system for space debris clearing," Acta Astron. 104, 243-255 (2014).

${ }^{45}$ C. R. Phipps and C. Bonnal, "A spaceborne, pulsed UV laser system for re-entering or nudging LEO debris, and re-orbiting GEO debris," Acta Astron. 118, 224-236 (2016).

${ }^{46}$ C. Phipps, C. Bonnal, F. Masson, M. Boustie, L. Berthe, S. Baton, E. Brambrink, J.-M. Chevalier, L. Videau, and S. Boyer, "Transfers from earth to LEO and LEO to interplanetary space using lasers," Acta Astron., Manuscript No. AA_2017_995 (submitted).

${ }^{47}$ J. Ihlemann, F. Beinhorn, H. Schmidt, K. Luther, and J. Troe, "Plasma and plume effects on UV laser ablation of polymers," Proc. SPIE 5448, 572-580 (2004).

${ }^{48}$ L. N. Myrabo, D. G. Messitt, and F. B. Mead, Jr., "Ground and flight tests of a laser propelled vehicle," AIAA Paper No. 98-1001, 1998.

${ }^{49} \mathrm{C}$. Phipps and J. Luke, "Laser space propulsion-Applications at two extremes of laser power," in Laser Ablation and Its Applications, Springer Series in Optical Sciences Vol. 129, edited by C. Phipps (Springer, New York, 2007), pp. 407-434.
${ }^{50}$ J. Sinko and C. Phipps, "Modeling $\mathrm{CO}_{2}$ laser ablation impulse of polymers in vapor and plasma regimes," Appl. Phys. Lett. 95, 131105 (2009).

${ }^{51}$ A. P. Papavlu, L. Urech, T. Lippert, C. Phipps, J. Hermann, and A. Wokaun, "fs Laser-induced plasmas from energetic polymers: Towards micro-laser plasma thruster application," Plasma Process. Polym. 13, 611-622 (2016).

${ }^{52} \mathrm{C}$. Phipps, "An alternate treatment of the vapor-plasma transition," Int. J. Aerosp. Innovations 3, 45-50 (2011).

${ }^{53}$ The SESAME equation-of-state database is maintained by group T-1 at Los Alamos National Laboratory, S. P. Lyon and J. D. Johnson, "SESAME: The Los Alamos National Laboratory equation of state database," LANL Report No. LA-UR-92-3407, 1992, see sesame@lanl.gov for additional information.

${ }^{54}$ C. Phipps, R. Harrison, T. Shimada, G. York, T. Turner, X. Corlis, H. Steele, L. Haynes, and T. King, "Enhanced vacuum laser-impulse coupling by volume absorption at infrared wavelengths," Laser Part. Beams 8, 281 (1990).

${ }^{55}$ C. Phipps and R. Dreyfus, "Laser ablation and plasma formation," in Laser Ionization Mass Analysis, Chemical Analysis Series Vol. 124, edited by A. Vertes, R. Gijbels, and F. Adams (Wiley, 1993), pp. 369-431.

${ }^{56} \mathrm{C}$. Phipps and J. Luke, in Proceedings of International Electric Propulsion Conference, Princeton, 30 October 2015, Paper No. IEPC 319, Fig. 5.

${ }^{57} \mathrm{~B}$. Poling, J. Prausnitz, and J. O'Connell, The Properties of Gases and Liquids, 5th ed. (McGraw-Hill, New York, 2001), pp. 7.9-7.11

${ }^{58} \mathrm{~L}$. Barker and R. Hollenbach, "Interferometer technique for measuring the dynamic mechanical properties of materials," Rev. Sci. Instrum. 36(11), 1617-1620 (1965).

${ }^{59}$ M. Durand and P. Laharrague, "System of velocity measurement of a projectile using a Fabry-Pérot interferometer," in Proceedings of Ninth International Congress on H.S Photographic Society of Motion Picture and Television Engineers (1970).

${ }^{60}$ O. T. Strand, D. R. Goosman, C. Martinez, T. L. Whitworth, and W. W. Kuhlow, "Compact system for high-speed velocimetry using heterodyne techniques," Rev. Sci. Instrum. 77(8), 083108 (2006).

${ }^{61}$ P. Mercier, J. Benier, A. Azzolina, J.-M. Lagrange, and D. Partouche, "Photonic Doppler velocimetry in shock physics experiments," J. Phys. IV 134, 805-812 (2006).

${ }^{62}$ S. Bardy, B. Aubert, L. Berthe, P. Combis, D. Hébert, E. Lescoute, J.-L. Rullier, and L. Videau, "Numerical study of laser ablation on aluminum for shock-wave applications: Development of a suitable model by comparison with recent experiments," Opt. Eng. 56(1), 011014 (2017).

${ }^{63}$ E. Palik, in Handbook of Optical Constants of Solids, edited by E. D. Palik (Academic, New York, 1985).

${ }^{64} \mathrm{~S}$. Atzeni and J. Meyer-Ter-Vehn, in The Physics of Inertial Fusion, edited by S. Atzeni and J. Meyer-Ter-Vehn (Oxford University Press, 2004).

${ }^{65}$ M. Povarnitsyn, N. Andreev, P. Levashov, K. Khishchenko, and O. Rosmej, "Dynamics of thin metal foils irradiated by moderate-contrast high intensity laser beams," Phys. Plasmas 19, 023110 (2012).

${ }^{66}$ S. Anisimov, G. Kapeliovich, and T. Perel'man, "Electron emission from metal surfaces exposed to ultrashort laser pulses," Sov. Phys. JETP 39, 375-377 (1974)

${ }^{67}$ M. Povarnitsyn, N. Andreev, E. Apfelbaum, T. Itina, K. Khishchenko, O. Kostenko, P. Levashov, and M. Veysman, "A wide range model for simulation of pump-probe experiments with metals," Appl. Surf. Sci. 258, 9480-9483 (2012).

${ }^{68}$ S. Scharring, R.-A. Lorbeer, and H.-A. Eckel, "Numerical simulations on laser-ablative micropropulsiomn with short and ultrashort laser pulses," Trans. Jpn. Soc. Aeronaut. Space Sci. 14, pp. Pb_69-Pb_75 (2016). 